\title{
Revisión de Chorizanthe R. Br. ex Benth. (Polygonaceae) en Chile
}

\section{Chorizanthe R. Br. ex Benth. (Polygonaceae) in Chile}

\author{
Sebastián Teillier ${ }^{1 *}$, Jorge Macaya-Berti ${ }^{2} \&$ Patricio Novoa ${ }^{3}$ \\ ${ }^{1}$ Escuela de Arquitectura del Paisaje, Universidad Central de Chile. Santa Isabel 1160, Santiago, Chile. \\ ${ }^{2}$ CEDREM Consultores. Padre Mariano 82. Providencia, Santiago, Chile. \\ 3Jardín Botánico Nacional. Camino El Olivar 305. Viña del Mar, Chile. \\ *steillier@gmail.com
}

\begin{abstract}
RESUMEN
Chorizanthe fue descrito por G. Bentham (1836) sobre la base de plantas recolectadas en Chile. Las primeras especies descritas fueron C. glabrescens Benth., C. macraei Benth., C. paniculata Benth., C. peduncularis Benth., C. vaginata Benth. y $C$. virgata Benth. J. Rémy (1851) las reconoce y agrega a $C$. frankenioides J. Rémy y a $C$. commissuralis J. Rémy. R.A. Philippi $(1864,1873,1895)$ describió unas dieciséis especies de las que aún se aceptan, $C$. dasyantha Phil, $C$. flavescens Phil., C. kingii Phil., C. umbellata Phil. y C. viridis. J. Reveal (2004) llevó a cabo una revisión y sinonimización de los tipos y propuso catorce especies como válidas para Chile; sin embargo, no revisó el género ni presentó claves de determinación. Teillier y Macaya (2018) describieron cinco especies en el marco de una revisión para el proyecto "Nueva Flora de Chile": C. gajardoi Teillier \& Macaya, C. mieresii Teillier \& Macaya, C. navasiae Teillier \& Macaya, C. novoana Teillier \& Macaya y C. rosasii Teillier \& Macaya. En este trabajo se describe una nueva especie, C. limariensis y se presenta una revisión, la primera integral, con el fin de proponer una hipótesis sobre la taxonomía del género. Para ello se han utilizado los métodos clásicos comparando tipos, material de herbario y ejemplares en terreno. Como resultado se propone que el género estaría formado por 19 especies, 18 subarbustos y hierbas perennes (subgénero Chorizanthe) y una anual (C. commissuralis, subgénero Amphietes). Se lectotipifica, además, a $C$. fasciculata Phil., C. kingii Phil., C. parviflora Phil., C. rosea Phil. y C. viridis Phil. Finalmente, se presentan una clave para diferenciar las especies, descripciones morfológicas y fotografías.
\end{abstract}

Palabras clave: Chorizanthe, Chorizanthe limariensis, Polygonaceae, Flora de Chile.

\begin{abstract}
Chorizanthe was described on collections from Chile by G. Bentham in 1836 and included C. glabrescens Benth., C. macraei Benth., C. paniculata Benth., C. peduncularis Benth., C. vaginata Benth. and C. virgata Benth. In 1851, J. Rémy recognized Bentham's species and added C. frankenioides J. Rémy and C. commissuralis J. Rémy. In a series of publications, (1864, 1873, 1895) R. A. Philippi described some sixteen species, of which, the following are accepted: C. dasyantha Phil, C. flavescens Phil., C. kingii Phil., C. umbellata Phil., and C. viridis Phil. In 2004, J. Reveal carried out a revision and recognized fourteen species as valid for Chile; however, it did not review the genus or provide keys of determination. In 2018, S. Teillier and J. Macaya described five species in the framework of a review for the "New Flora of Chile" project: $C$. gajardoi Teillier \& Macaya, C. mieresii Teillier \& Macaya, C. navasiae Teillier \& Macaya, C. novoana Teillier \& Macaya and C. rosasii Teillier \& Macaya. In this paper, we describe a new species, C. limariensis, and we provide a review of the Chilean species where we propose a hypothesis about the taxonomy of the genus. For this treatment, classical methods have been used, comparing types, herbarium material and specimens in the field. These results result in a genus that comprises 19 species; 18 species of subshrubs and perennial herbs (subgenus Chorizanthe) and an annual herb (C. commissuralis in subgenus Amphietes). We propose also lectotypes for C. fasciculata Phil., C. kingii Phil., C. parviflora Phil., C. rosea Phil. and $C$. viridis Phil. Finally, a key to species, morphological descriptions, and photographs are presented.
\end{abstract}

KeYwords: Chorizanthe, Chorizanthe limariensis, Polygonaceae, Flora of Chile. 


\section{INTRODUCCIÓN}

Chorizanthe R. Br. ex Benth. es un género de Polygonaceae que pertenece a la subfamilia Eriogonoideae (Reveal, 1978), tribu Chorizanthiinae (Reveal, 2005); de acuerdo con Hardham \& Reveal (1989) reúne al menos unas cincuenta especies leñosas o herbáceas.

Los límites del género fueron explorados sobre la base de estudios de ADN por Kempton (2012); sus resultados sugieren conservar los límites actuales del género; sin embargo, deja establecida la dificultad para definir si se debiera incluir en él a las especies del género Lastarriaea, de las que solo L. chilensis J. Rémy, crece en el país. Respecto de las especies chilenas de Chorizanthe, en el análisis se incluyen apenas dos, $C$. dasyantha Phil. y $C$. frankenioides J. Rémy, ambas se ubicaron dentro de los límites del género y en el mismo clado.

La taxonomía clásica ha incluido a las especies nativas leñosas y perennes en el subgénero Chorizanthe; la única especie anual, C. commissuralis J. Rémy, se incluyó en el subgénero Amphietes Rev. et Hardham (Hardham \& Reveal, 1989).

Las primeras especies de Chorizanthe fueron descritas por G. Bentham (1836) sobre la base de plantas recolectadas en Chile por H. Cumming y J. Macrae; dichas especies fueron C. glabrescens Benth., C. macraei Benth., C. paniculata Benth., C. peduncularis Benth., C. vaginata Benth. y $C$. virgata Benth, siendo esta última la especie tipo del género. Más tarde, J. Rémy (1851), revisa el género, reconoce las especies de Bentham y agrega a $C$. frankenioides J. Rémy y a $C$. commissuralis J. Rémy, la única especie anual que se ha descrito para Chile. Finalmente, R. A. Philippi (1864, 1873, 1895) describió unas dieciséis especies de las que aún se aceptan, $C$. dasyantha Phil, C. flavescens Phil., C. kingii Phil., C. umbellata Phil. y C. viridis Phil. Recientemente J. Reveal (2004) llevó a cabo una revisión y sinonimización de los tipos, cuyos resultados sirvieron de base a Zuloaga et al. (2008), para proponer catorce especies como válidas para Chile, sin embargo, no revisó el género ni presentó claves de determinación.

Chorizanthe tiene una distribución geográfica disyunta que incluye el suroeste de los Estados Unidos (mayormente California) y el norte y centro de Chile. Una sola especie, $C$. commissuralis crece en el sur de Perú (Hardham \& Reveal, 1989; Brako \& Zarucchi, 1993) y en el noroeste de Argentina (San Juan) (Cialdella, 1992, 1994). En relación con el hábito, es notable que en América del Norte predominen las hierbas anuales, en tanto que en Chile, predominan las hierbas perennes y los subarbustos (Reveal, 1978).

En Chile las especies de Chorizanthe se distribuyen entre las regiones de Arica-Parinacota y del Maule, con una importante riqueza de especies concentrada en la Región de Coquimbo. En el norte del país crecen preferentemente en los matorrales de las dunas del litoral y en los matorrales esteparios, interiores, de las regiones de Atacama y Coquimbo; en la zona central, se encuentran como parte de los matorrales esclerofilos y de la vegetación de las dunas litorales.

Dada la ausencia de una revisión del género desde los tiempos de Claudio Gay (1851), el objetivo de este trabajo es proveer un tratamiento exhaustivo del género para aportar al proyecto de la "Nueva Flora de Chile". Se espera que este trabajo sea la base de estudios filogenéticos que lo validen o sirvan para proponer nuevas hipótesis.

\section{METODOLOGÍA}

Se utilizó la metodología clásica, comparativa, de la taxonomía. Se revisaron las descripciones de las especies que figuran en los trabajos de Bentham (1836), J. Rémy en Gay (1851) y Philippi $(1864,1873,1895)$ y se examinaron los tipos disponibles, tanto en el Museo Nacional de Historia Natural (SGO) como en forma digital, particularmente los proveídos por el sitio Jstor-Global Plants (https://about. jstor.org) y por los herbarios P, K, G, GH, NY, BM, entre otros.

Para tener un mejor conocimiento de las plantas vivas y recolectar material de herbario, los autores llevaron a cabo dos excursiones, una en noviembre de 2016 por el litoral de las regiones de Coquimbo y de Atacama, y otra por el interior, desde el valle del río Petorca hasta el del Elqui, en noviembre de 2017. Además, se revisó el material de Chorizanthe disponible en los herbarios CONC, JBN y SGO (los acrónimos de acuerdo con el Index Herbariorum) y la colección deplantas de la estación IntihuasidelINIA(Vicuña).

\section{RESULTADOS}

En el país crecen 19 especies de Chorizanthe, 13 leñosas o subleñosas, cinco hierbas perennes y una hierba anual.

Chorizanthe R. Br. ex Benth., Trans. Linn. Soc. London 17: 416. 1836.

TIPO: Chorizanthe virgata Benth., lectotipo designado por Goodman, Ann. Missouri Bot. Gard. 21: 19. 1934.

Subarbustos con forma de vida de tipo caméfito, capaces de secarse completamente en la parte aérea o hierbas perennes con la capacidad de rebrotar desde un caudex basal subterráneo leñoso; solo una especie es una hierba anual. Tallos tendidos o erguidos. Hojas sésiles, alternas o todas basales, simples, a veces diferenciadas en lámina y vaina (Font Quer, 1982); lámina entera, frecuentemente revoluta; sin ócreas. Inflorescencia, una cima dicótoma (dicasio) desde 2-3 veces hasta muy complejamente ramificada, ramas abiertas o cerradas, laxas o congestionadas, formando 
sinflorescencias cuyo aspecto final es frecuentemente el de una inflorescencia de tipo monopodial como una umbela simple o compuesta, una panoja o un glomérulo. Pedúnculo floral 2-3 ramificado, raras veces sin ramificaciones, con 2-3 brácteas en la base, similares a las hojas, pero menores; en cada dicotomía y en cada flor hay dos o tres bractéolas libres (C. commissuralis) o concrescentes en la base; las dicotomías son unifloras a trifloras. Involucro sésil, tubular, unifloro, gamofilo, con seis lóbulos cortos generalmente de largo desigual, terminados en apéndices más o menos uncinados; los lóbulos con una nervadura central marcada (costilla) y un retículo conspicuo con nervaduras longitudinales y transversales. Perigonio cortamente pedunculado, gamotépalo, petaloide, tépalos seis, generalmente blancos o rosados, tubo floral con un anillo de glándulas nectaríferas amarillentas en la garganta, piloso o casi glabro; androceo con seis o nueve estambres, éstos con los filamentos unidos a la base del perigonio y pilosos en la base; gineceo con ovario súpero, unilocular; estilos tres; estigmas, tres, capitados. Polinización entomófila. Fruto, un aquenio triquetro, apenas diferente entre las especies; involucro endurecido, con los ganchos apicales fuertemente esclerificados que participan en la dispersión del fruto que es epizoocoro.

Mediante la siguiente clave es posible distinguir entre las especies de Chorizanthe y las de los géneros afines:

1. Involucro con dos o más flores en su interior................... xytheca

1 '. Involucro con una sola flor.......................................................

2. Perigonio membranáceo de color blanco o rosado. Estambres

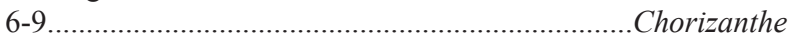
2.' Perigonio coriáceo, amarillo-verdoso. Estambres 3.

.Lastarriaea

En Chile crecen especies de dos subgéneros, Chorizanthe (18) y Amphietes (1), este último reúne especies anuales en su mayor parte norteamericanas (Reveal \& Hardham 1989).

Clave para identificar a las especies de Chorizanthe en Chile

1. Hierbas anuales. Hojas no diferenciadas en vaina y lámina. Bractéolas libres

C. commissuralis

1. Subarbustos o hierbas perennes, a veces leñosas en la base. Hojas frecuentemente diferenciadas en vaina y lámina. Bractéolas concrescentes en su base......

2. Hierbas perennes. Tallos aéreos siempre herbáceos y generalmente floríferos, similares a un escapo. Las hojas, en su mayor parte, forman un "césped" o una roseta basal.

2. Subarbustos. Tallos aéreos leñosos, raras veces, débilmente leñosos, secos casi por completo en los años que no llueve, floríferos o

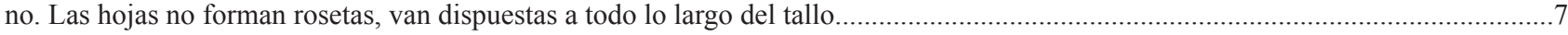

3. Sinflorescencias ampliamente desplegadas con aspecto de panículas laxas...............................................................................4

3. Sinflorescencias contraídas con aspecto de glomérulos o de umbelas.

4. Hojas apenas pilosas, de color verde.

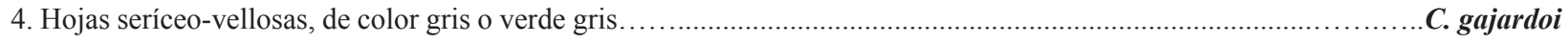
5. Hojas agrupadas en rosetas flojas, dispuestas sobre ramas horizontales o ascendentes. Sinflorescencias muy densas y

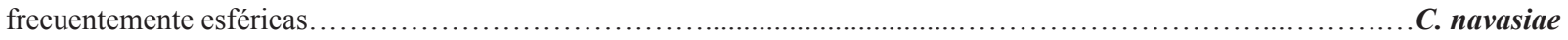
5. Hojas dispuestas en rosetas muy apretadas; no hay tallos horizontales. Sinflorescencias de otras formas..................6

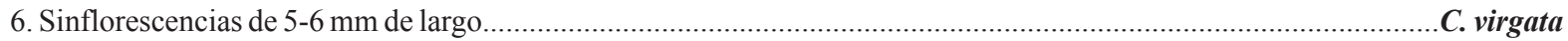

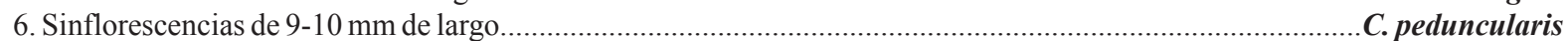

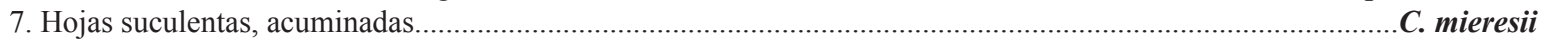

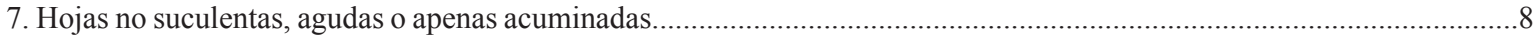

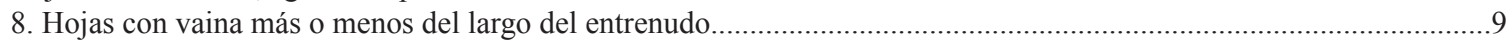

8. Hojas con vaina más breve, de forma anular o no envainadoras..........................................................................13

9. Flores de color rosado. Plantas con hojas densamente tomentosas, grises; vaina de la hoja con el margen superior membranoso-lacerado................................................................................................................ dasyantha 9. Flores de color generalmente blanco. Plantas con hojas pilosas a glabrescentes; vaina con el margen superior ni

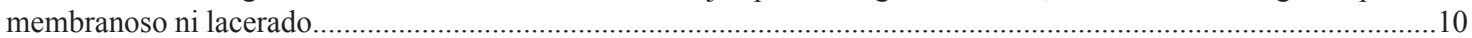

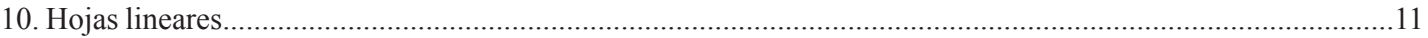

10. Hojas romboidales, a veces, lanceoladas, muy raras veces lineares..........................................................12 11. Plantas frecuentemente pulvinadas. Ramificaciones muy leñosas, la base gruesa. Involucro densamente piloso.

C. limariensis

11. Plantas no pulvinadas. Ramificaciones apenas leñosas, delgadas, tallos tendidos, raras veces erguidos. Involucro glabro.

C. glabrescens

12. Arbustos con ramas erguidas.

C. frankenioides

12. Arbustos con ramas tendidas (plantas pulvinadas) ................................................................ vaginata

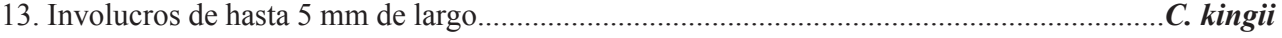

13. Involucros demás de $5 \mathrm{~mm}$ de largo.

14. Sinflorescencias en panojas desplegadas, muy ramificadas.

C. paniculata

14. Sinflorescencias con aspecto de umbelas simples o compuestas.. 15 
15. Hojas verde-grisáceas, densamente pilosas........................................................................16 16. Tallos leñosos breves. Hojas verdes, pilosas, nunca hirsuto-lanosas; base casi glabra, rojiza. En las cordilleras, en ambiente subandino y andino ..................................... rosasii 16. Tallos leñosos más largos, raras veces breves. Hojas grises, hirsutas, base densamente hirsuta, blanquecina. Valles interiores en ambiente montano y subandino, raras veces en ambiente andino...

17. Sinflorescencias contraídas, con aspecto de glomérulos densos o algo desplegadas a modo de panojas. Pedúnculos generalmente solitarios. C. macraei 17. Sinflorescencias, en cimas con aspecto de umbelas; pedúnculo 2-3 veces ramificado...... ...18

18. Tallos erguidos, verticales. Involucros glabrescentes.......................... umbellata 18. Tallos frecuentemente horizontales. Involucros densamente

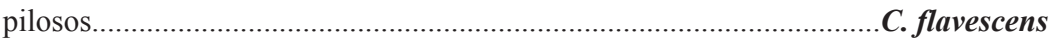

\section{Subgénero Chorizanthe}

I.1. Chorizanthe dasyantha Phil., Linnaea 33: 227. 1864. TIPO: San Felipe de Aconcagua, 01-01-1863, Landbeck s.n., (lectotipo SGO 47954!, designado por Reveal, Harvard Pap. Bot. (1): 147, 2004).

Chorizanthe rosea Phil., Linnaea 33: 225. 1864. TIPO: "Prope Quilimari in prov. Aconcagua leg. orn. Landbeck ", (lectotipo SGO 47973! aquí designado; isolectotipo, SGO 38658!).

Chorizanthe fasciculata Phil., Anales Univ. Chile 91: 497.1895. TIPO: "Prope La Ligua in regione litorali provinciae Aconcagua invenit orn. G. Flühmann, Februaris 1887" (lectotipo SGO 47966! aquí designado; isolectotipo SGO 38661!).

Arbustos, con ramas de hasta $120 \mathrm{~cm}$ de alto. Tallos densamente pilosos, tricomas grisáceos. Hojas grises, tomentosas, con las vainas bien diferenciadas, pilosas, con el borde membranoso y lacerado; láminas también pilosas, aovado-lanceoladas, de 1,4-2,4 x 0,2-0,3 cm, débilmente mucronadas. Los dicasios se ramifican y forman una sinflorescencia terminal con los pedúnculos basales desde brevísimos hasta bien desarrollados; brácteas foliáceas, dispuestas de a pares, de 1-1,1 x 0,1 cm; bractéolas rojizas, dispuestas también en pares, densamente pilosas en el margen y en el envés, aovado-lanceoladas, de 3-4 $\mathrm{mm}$ de largo, acuminadas; involucros de color marrón, apenas reticulados, densamente hirsuto-pilosos, de $5 \mathrm{~mm}$ de largo, interior glabro; los lóbulos terminan en apéndices desiguales, muy pilosos, uncinados, de 0,8-1,2 $\mathrm{mm}$. Perigonio rosado, de 5-5,5, mm; tépalos pilosos en la nervadura central, tubo con el anillo de glándulas evidente. Estambres 9. Aquenio de alrededor de $4 \mathrm{~mm}$ (Figs. 1 y 2).

\section{DisTRIBUCIÓN GEOGRÁFICA}

Crece en el litoral de la provincia de Choapa, Región de Coquimbo, entre las localidades de Huentelauquén, Los Vilos y Pichidangui (desembocadura del estero Quilimarí). Se la encuentra en los matorrales que se forman en las dunas estabilizadas.
OBSERVACIONES

La localidad del tipo de $C$. dasyantha informada por Philippi (1864), "San Felipe de Aconcagua", se encuentra fuera del área de distribución natural de la especie. El ejemplar designado como tipo por Rebeca Acevedo de Vargas disponible en SGO 47954, tiene en su etiqueta la leyenda "Prov. Aconcagua. 1862. Landbeck". La fotografía que provee el Field Museum (F0BN018416) parece corresponder a un isotipo, pero no está atribuido a Landbeck.

Ejemplares con las ramas tendidas, ramillas secundarias similares a braquiblastos y una sinflorescencia más corta y densa, frecuentes en la localidad de Pichidangui, fueron descritos por R.A. Philippi como C. rosea Phil., pero se observó en terreno que la mayor parte de las diferencias propuestas caen dentro de la variabilidad natural de $C$. dasyantha. En la fotografía de tipos del herbario de Berlín distribuida por Field Museum (F0BN018423), hay dos ejemplares de $C$. rosea, que aparentemente corresponden a uno o dos isotipos destruidos. Se ha lectotipificado a SGO 47973 como lectotipo de C. rosea porque Reveal (2004) no especifica cuál de los ejemplares corresponde al lectotipo.

El tipo de C. fasciculata Phil. es una planta similar a $C$. dasyantha, pero con la inflorescencia más desplegada. La localidad reportada por Flühmann, "litoral de La Ligua" es dudosa puesto que la distribución observada de $C$. dasyantha alcanza por el sur solo hasta la localidad de Pichidangui. Reveal (2004) designa un holotipo en SGO, pero no repara en que hay dos ejemplares en SGO que son posibles "tipo", por ello se lo ha lectotipificado.

\section{Material estudiado}

CHILE, Región de Coquimbo, prov. Choapa, Huentelauquén, 09-XI-1954, C. Jiles 2679 (CONC). Huentelauquén, 20-X1955, C. Jiles 2797 (CONC). Huentelauquén, $1 \mathrm{~km}$ al norte, 29-I-1991, M. De Vore 1566 (CONC). Chigualoco, 29-XI1961, R. Wagenknecht 937 (CONC). Chigualoco, $15 \mathrm{~m}$ s.n.m., 14-XI-2016, S. Teillier, J. Macaya, P. Novoa \& O. Fernández 8186 (CONC). Cerca de Agua Amarilla, $7 \mathrm{~km}$ al norte de Los Vilos, 2-XI-1974, C. Marticorena, O. Matthei 
\& R. Rodríguez 346 (CONC). Los Vilos, sector Mal Paso, 65 m s.n.m., 13-XI-2016, S. Teillier, J. Macaya, P. Novoa \& O. Fernández 8185 (CONC, SGO). Norte de los Vilos, km 235, 24-X-1987, M. Muñoz \& I. Meza 2206 (SGO). 6 $\mathrm{km}$ al norte de Los Vilos, 16-X-1971, C. Marticorena, R. Rodríguez \& E. Weldt 1361. (CONC). Los Vilos, 1896, G. Geisse s/n (SGO 09582). Los Vilos, I-1899, K. Reiche s/n (SGO 047992). Los Vilos, 20 m s.n.m., 08-X-1965, G.
Montero 7226 (CONC). Los Vilos, 25 m s.n.m., X-1965, A. Kohler 200 (CONC). 0,2 km al norte de Los Vilos, 25 m s.n.m., 16-I-1989, T.G. Lammers, R. Rodríguez \& C.M. Baeza 6333 (CONC). Los Vilos, 12-XI-2011, P. Novoa 735 (JBN). Pichidangui, 20-II-1960, M. Mahu 1837 (CONC). Pichidangui, 12-XI-1961, A. Garaventa 6188 (CONC). Pichidangui, 15 m s.n.m., 13-XI-2016, S. Teillier, J. Macaya, P. Novoa \& O. Fernández 8182 (CONC).

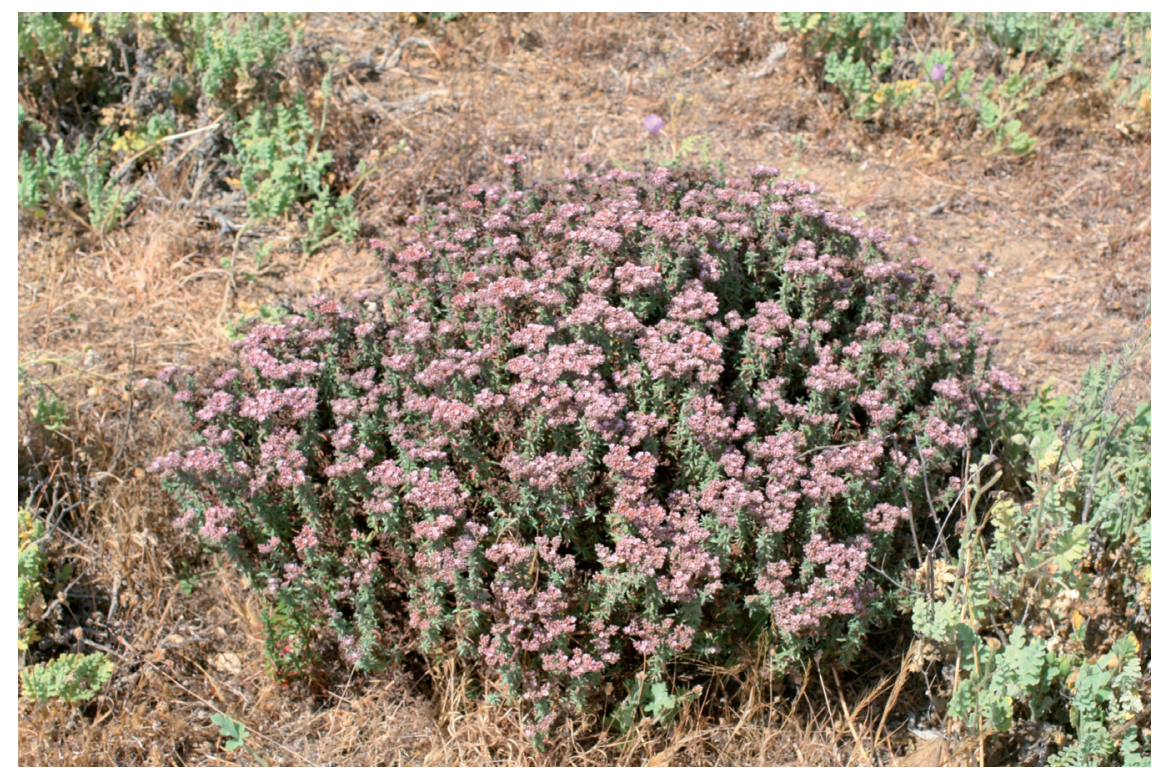

Figura 1: Chorizanthe dasyantha, hábito de una planta florecida. Chigualoco, $\mathrm{N}$ de Los Vilos, Región de Coquimbo. Fotografía de $\mathrm{S}$. Teillier. / Chorizanthe dasyantha, habit of a flowering plant. Chigualoco, N Los Vilos, Región de Coquimbo. Photo S. Teillier.

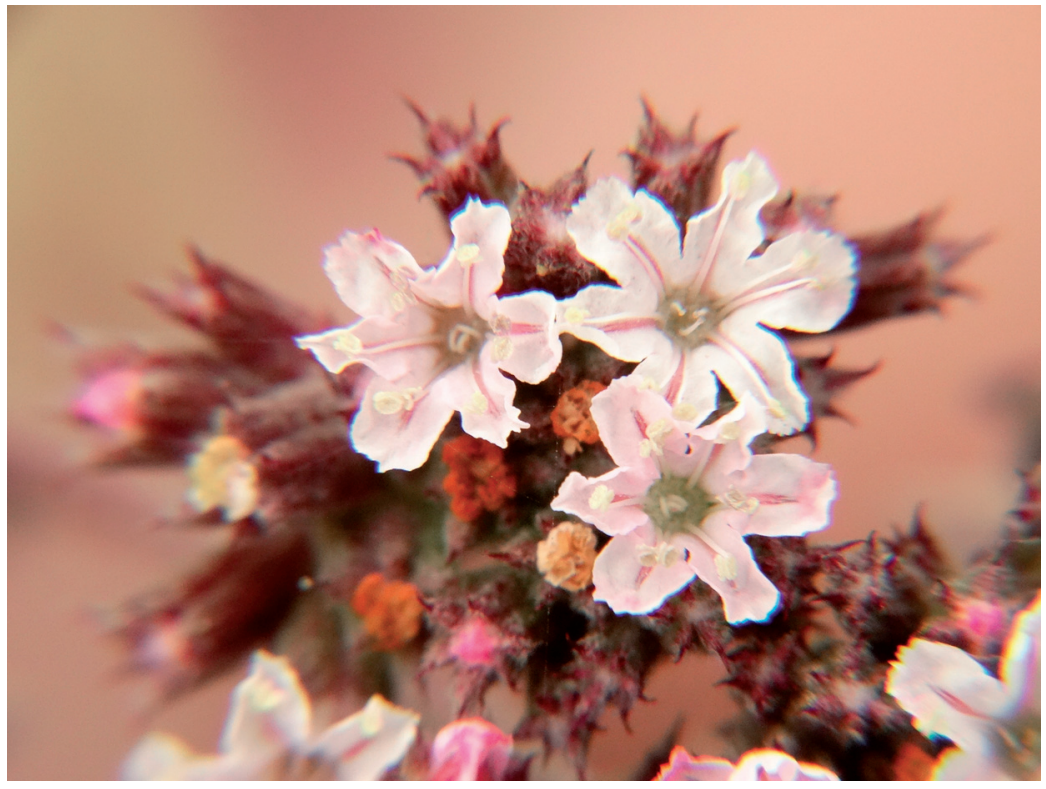

Figura 2. Chorizanthe dasyantha, parte superior de la sinflorescencia con detalle de las flores perigoniadas. Chigualoco, N de Los Vilos, Región de Coquimbo. Fotografía de O. Fernández. / Chorizanthe dasyantha, the upper part of a synflorescence and a detail of the perigonium. Chigualoco, N Los Vilos, Región de Coquimbo. Photo: O. Fernández. 
I. 2. Chorizanthe flavescens Phil., Linnaea, 33: 226. 1864. TIPO: "Prope Illapel crescit" Landbeck s.n. (holotipo, SGO 47988!).

Chorizanthe illapelina Phil., Anales Univ. Chile 91: 497. 1895. TIPO: "Habitat prope Illapel; aestate 1884 lecta fuit" (no hay mención del colector) (holotipo, SGO 47999!).

Subarbusto de 15-20 cm de alto; tallos aéreos leñosos, verticales o ascendentes. Hojas seríceas en ambas caras; las vainas, apenas anulares, con el margen superior oblicuo y ciliado; las láminas, linear-lanceoladas, de 5-15 x 0,8-1 mm. Los dicasios forman una sinflorescencia umbeliforme densa hasta esférica; pedúnculos erguidos, generalmente bien destacados, de 2-12 cm de largo, ramificados en dos o tres; brácteas similares a las hojas, dispuestas en verticilos de 2 ó 3; bractéolas en pares, concrescentes por la base, de 2,5$3 \times 1 \mathrm{~mm}$. Involucros densamente blanco-lanosos a marrón rojizos a su madurez, de $5-10 \mathrm{~mm}$ de largo; retículo oculto por la pilosidad, lóbulos apicales desiguales y fuertemente uncinados. Perigonio de 2-4 $\mathrm{mm}$, anillo de glándulas presente; tépalos blancos, pilosos en el exterior. Estambres 6 (Fig. 3).

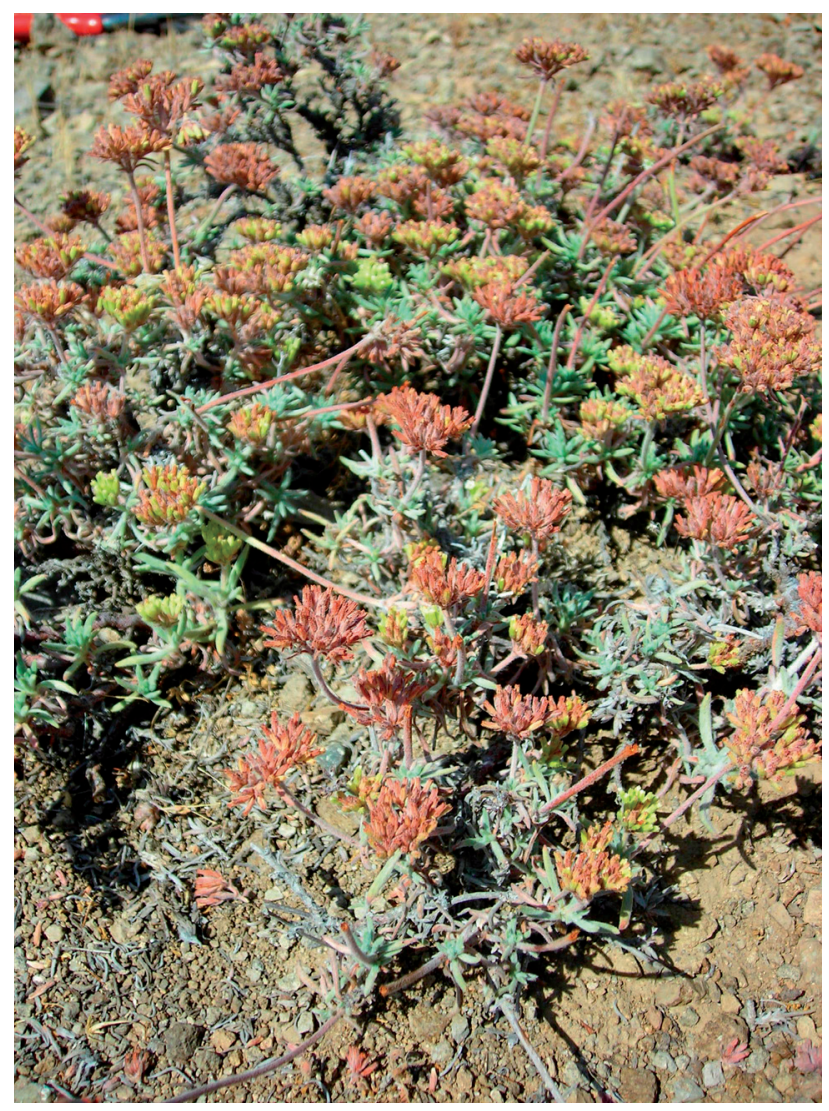

Figura 3. Chorizanthe flavescens, hábito de la planta en la fase de formación de frutos. Portezuelo de la cuesta que une Alicahue con Chincolco, Región de Valparaíso. Fotografía de O. Fernández. / Chorizanthe flavescens, habit of a plant during fruit formation. Road to Chincolco, Región de Valparaíso. Photo: O. Fernández.
DisTRIBUCIÓN GEOGRÁFICA

Endémica, habita entre las regiones de Coquimbo y Valparaíso.

\section{OBSERVACIONES}

Al revisar los especimenes estudiados encontramos tres variaciones, no relacionadas con la latitud ni con la altitud, por lo que se mantiene un solo taxón que podría separarse en tres formas:

a. Ejemplares similares al tipo de C. flavescens que se coleccionaron en la cuesta de Alicahue (C. Muñoz \& G.L. Stebbins 8670, M. Muñoz 3301 y O. Fernández 559) y ejemplares recolectados entre Salamanca e Illapel (C. Marticorena \& O. Matthei 419).

b. Ejemplares con las inflorescencias muy densas y esféricas, con el involucro densamente piloso, tales como Jiles 1806 (Las Tunas, 450 m s.n.m., 10-IX1950) y Teillier et al. 8296, del camino de Combarbalá a Montepatria.

c. Ejemplares similares al tipo de C. illapelina (Jiles 2791) que difieren notablemente de los anteriores por tener una menor densidad de pelos en el involucro, la que deja ver el retículo, y por la sinflorescencia más desplegada.

Superficialmente semeja también a $C$. umbellata, de la que se distingue por las ramificaciones principales frecuentemente horizontales y por el involucro densamente hirsuto.

Material estudiado

CHILE, Región de Coquimbo, prov. Limarí, Las Tunas, 450 m, 10-IX-1950, C. Jiles 1806 (CONC). El Talhuén, 6-X1955, C. Jiles 2791 (CONC). Ovalle, en los cerros, 3-X1940, E. Barros 3727 (CONC). Camino de Combarbalá a Monte Patria, km 27,7, embalse Cogotí, 740 m, 09-XI2017, S. Teillier, J. Macaya, P. Novoa \& O. Fernández, 8296 (CONC). Prov. Choapa, Entre Illapel y Los Vilos, 19-X-1963, C. Marticorena \& O. Matthei 419 (CONC). SalamancaIllapel, 23-IX-1952, E. Barros s/n (CONC 14059). Región de Valparaíso. Prov. Petorca, camino entre El Sobrante y Alicahue, cresta del cerro Gredas, 1350 m, 20-X-1973, C. Muñoz \& G.L. Stebbins 8670 (SGO). Cima de la cuesta de Alicahue, 1250 m, 10-X-1993, M. Muñoz 3301 (SGO). Cuesta Chincolco-Alicahue, 6-II-2007, O. Fernández 559 (JBN, CONC). Camino de Alicahue a Chincolco, cima de la cuesta, 1115 m, 06-XI-2017, S. Teillier, J. Macaya, P. Novoa \& O. Fernández, 8297 (CONC).

I. 3. Chorizanthe frankenioides J. Rémy, Hist. Fís. Pol. Chile, Bot. 5: 288. 1851-1852. TIPO: Chile, prov. Coquimbo, "La Serena, dans les sables du bord de la mer," C. Gay $s / n$. Octubre de 1838 (holotipo, $\mathrm{P}$ cb 00734190!; isotipos, F cb 0360585F!, G cb 00437272!, K cb 000532033!, GH cb 00036111, LE cb 00001649!, MEL cb 2366519!, NY cb 00285671!, SGO 47947!). Subarbustos; tallos floríferos 
erectos de (10-)20-50(-100) cm. Hojas algo carnosas, glabras, salvo la vaina, muy evidente en esta especie, que es ciliada; láminas de forma muy variable desde romboide hasta estrechamente lanceolada, de 0,6-1,5 (2) x 0,1-0,3 $\mathrm{cm}$; ápice agudo. Los dicasios forman una sinflorescencia similar a una umbela laxa; pedúnculo basal desde casi ausente a $5 \mathrm{~cm}$ de largo, bifurcado; brácteas en verticilos de a dos, subglabras, lineares, de 1-1,5 x 0,1 cm, mucronadas; bractéolas en verticilos de tres, ralamente pilosas, lanceoladas, de 4-5 $\mathrm{mm}$ de largo, mucronadas. Involucro de 6-7 $\mathrm{mm}$ de largo, retículo evidente, de color amarillo, lóbulos terminados en ganchos uncinados. Perigonio de 5-6 $\mathrm{mm}$, anillo de glándulas evidente, ralamente piloso; tépalos blancos, glabros; estambres, nueve. Aquenio glabro, con tres nervios marcados, de 4 mm (Fig. 4).

\section{DisTRIBUCIÓN GEOGRÁFICA}

Crece en la Región de Coquimbo, entre la quebrada de Juan Soldado y el balneario de Tongoy.

\section{OBSERVACIONES}

Arbusto psamófilo con distribución acotada al litoral, donde crece en las dunas consolidadas. Es muy conspicuo frente a la localidad de Las Tacas donde forma colonias extensas. Fue propuesto como una especie vulnerable al nivel regional (Squeo et al., 2001), pero las ilustraciones de dicha publicación corresponden a $C$. mieresii Teillier et Macaya. Es una especie localmente abundante, pero con una distribución muy restringida a un área fuertemente presionada por las inmobiliarias.

La colección más antigua de esta especie es un ejemplar de Lord Colchester, proveniente de Coquimbo, de 1831, anotado en una carpeta bajo el número 904 de Cumming; el ejemplar está pegado en la carpeta junto al tipo de C. glabrescens y a uno de Lastarriaea chilensis y está depositado en el herbario del Kew Garden (K000532030); dicho ejemplar se encuentra en el extremo derecho de la carpeta y tiene una etiqueta de J. Reveal (1988) con la identificación " $C$. frankenioides". Bentham pasó por alto el material o lo confundió con $C$. glabrescens, por ello la especie fue descrita, más tarde por J. Rémy, con base en material coleccionado por C. Gay. Se estudió un isotipo disponible en SGO (SGO 47947) cuya etiqueta tiene la leyenda manuscrita de Gay "Trigonocarpus in maritimus Serena, noviembre 1836. Chorizanthe frankenioides".

\section{Material estudiado}

CHILE. Región de Coquimbo, prov. Elqui, dunas frente a Juan Soldado, 8-I-1967, M. Ricardi, C. Marticorena \& O. Matthei, 1814 (CONC). Las Compañías, 17-IX-1947, B. Sparre 2572 (SGO). La Herradura, 75 m s.n.m., 16-XI2016, S. Teillier, J. Macaya, P. Novoa \& O. Fernández 8196 (CONC). $2 \mathrm{~km}$ antes de Pan de Azúcar, $100 \mathrm{~m}$ s.n.m., 11-I-1973, C. Marticorena, O. Matthei \& M. Quezada,
627 (CONC). Salida norte de La Serena, 9-X-2010, P. Novoa s/n (JBN 1628). Las Tacas, Lagunillas, $30 \mathrm{~m}$ s.n.m., IX-2009, A. Cea s/n (CONC 173064). Las Tacas, 30 m s.n.m., 16-XI-2016, S. Teillier, J. Macaya, P. Novoa \& O. Fernández 8194 (CONC). Guanaqueros, 110 m s.n.m., 16-XI-2016, S. Teillier, J. Macaya, P. Novoa \& O. Fernández 8193 (CONC). Guanaqueros, 100 m s.n.m., 15-XI-1961, C. Jiles 3919 (CONC). Morrillos, en dunas, 30-X-1966, A. Kohler 589 (CONC). Camino de La Serena a Ovalle, por Las Cardas km 5, Pan de Azúcar, 11-II-1988, C. Marticorena, T. Stuessy \& M. Baeza 9949 (CONC).

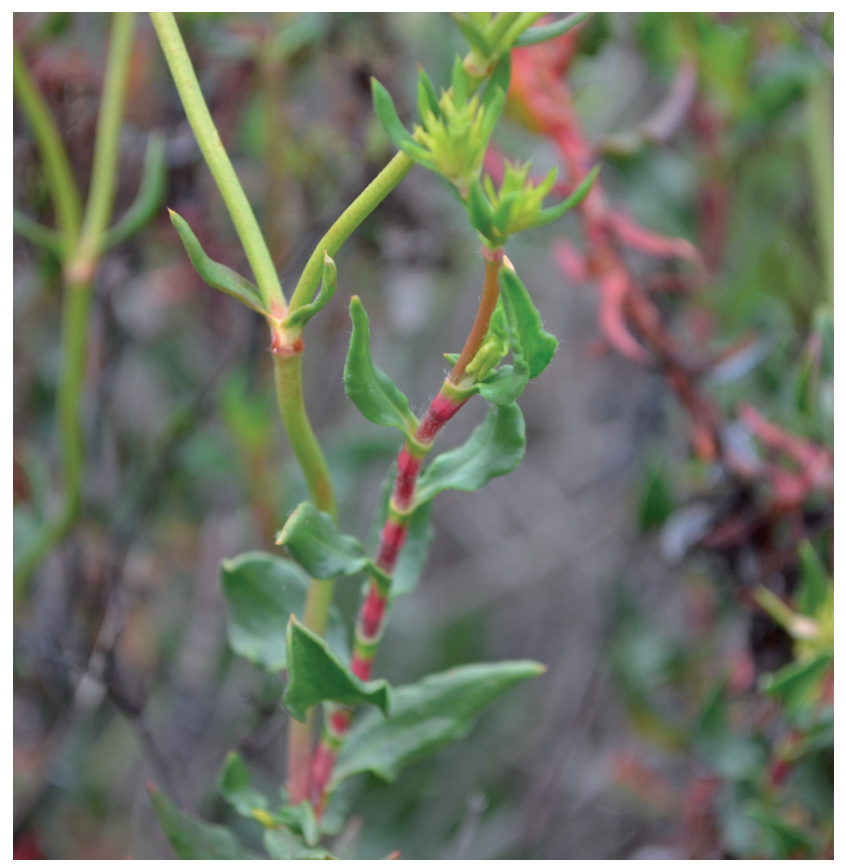

Figura 4. Chorizanthe frankenioides, parte de la planta mostrando el tallo rojizo y la hoja provista de lámina y vaina. $\mathrm{N}$ de Tongoy, Región de Coquimbo. Fotografía de M. Rosas. / Chorizanthe frankenioides, middle part of a plant showing the red stem and the leaf with differentiate sheath and blade. $\mathrm{N}$ of Tongoy, Región de Coquimbo. Photo: M. Rosas.

I.4. Chorizanthe gajardoi Teillier \& Macaya, Novon 26: 38. 2018. TIPO: Chile. Región de Coquimbo, prov. Choapa, quebrada de Cárcamo, cerros a $4 \mathrm{~km} \mathrm{~S}, 1900 \mathrm{~m}$ s.n.m., 6-XII-2011, J. Macaya, R. Bustamante \& M. Sepúlveda 3017 (holotipo, CONC!; isotipos SGO!, JBN!).

Hierbas perennes, provistas de rizomas poco ramificados. Tallos aéreos floríferos no leñosos, de hasta $10 \mathrm{~cm}$ de largo. Todas las hojas aglomeradas en la base, lámina seríceovellosa en ambas caras, linear-lanceolada, de 20-30 x 1-2 mm, apenas mucronada. Los dicasios forman una sinflorescencia de tipo panícula laxa, muy extendida y ramificada, con pedúnculos de hasta $12 \mathrm{~cm}$ de largo, ramificados en dos o tres 
brazos; brácteas foliáceas, de a tres por nudo, mucronadas; bractéolas dispuestas de a pares, de color castaño-rojizo, ciliadas, de 4 × 0,8-1 mm, acuminadas. Involucro de $5 \mathrm{~mm}$ de largo; blanquecino, externamente seríceo; retículo muy evidente, tanto en la parte externa como en la interna, apéndices seríceo-vellosos, ápice apenas uncinado. Perigonio de $3 \mathrm{~mm}$ de largo, tépalos blancos, seríceovellosos en el exterior y el interior, glabro; tubo con el anillo de glándulas piloso (Fig. 5).

\section{DisTRIBUCIÓN GEOGRÁFICA}

Especie endémica de la Región de Coquimbo, conocida hasta el momento solo de la quebrada de Cárcamo, tributaria del río Illapel, en la provincia de Choapa. Crece en las laderas de exposición norte, en matorrales ubicados en sitios algo rocosos, soleados; sus acompañantes leñosos en el área son, principalmente, Adesmia hystrix Phil., Chaetanthera glandulosa J. Remy, Haplopappus pinea (Phil.) Reiche, Mulguraea cinerascens (Schauer) N. O’Leary \& P. Peralta y Viviania marifolia Cav.

\section{OBSERVACIONES}

Si bien es algo similar a $C$. peduncularis Benth. difiere de ésta por su carácter no leñoso de la parte aérea y por la inflorescencia que tiene los pedúnculos más largos y mucho más ramificados. La roseta de hojas es similar a la de $C$. virgata Benth, pero se distingue de ella por sus sinflorescencias similares a una panoja muy ramificada.

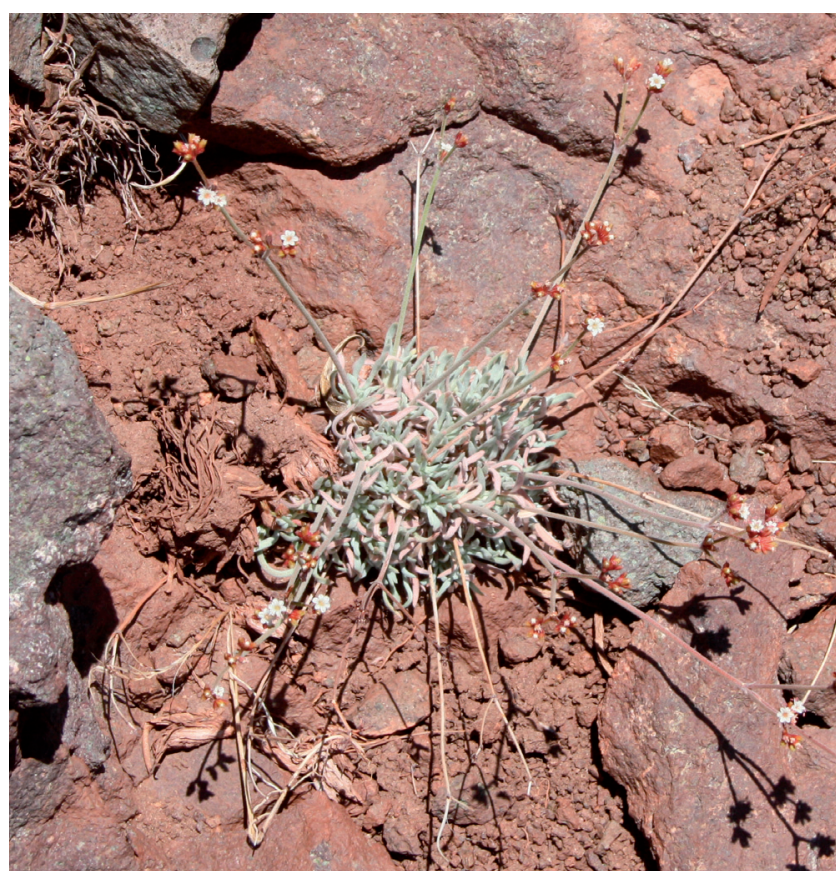

Figura 5. Chorizanthe gajardoi, hábito de una planta florecida. Quebrada de Cárcamo, cuenca del Choapa, Región de Coquimbo. Fotografía de J. Macaya. / Chorizanthe gajardoi, habit of a flowering plant. Quebrada de Cárcamo, Choapa valley, Región de Coquimbo. Photo: J. Macaya.
MATERial estudiado

CHILE, Región de Coquimbo, prov. Choapa, quebrada de Cárcamo, 1874 m s.n.m., 23-IX-2014, M. Rosas 8793 (CONC). Altos de Cárcamo a Maquehua, 1890 m s.n.m., 29-X-2014, M. Rosas 8884 (CONC).

I.5. Chorizanthe glabrescens Benth.,Trans. Linn. Soc.: 17(3): 418. 1836. TIPO: Coquimbo, Chili. Lord Colchester, Cuming n 904 (holotipo K cb 000532032!, isotipos BM, TCD).

Chorizanthe vaginata Benth. var. arida J. Rémy, Hist. Fís. Pol. Chile, Bot. 5: 288. 1851. TIPO: La Serena, C. Gay 1815, 1836 (lectotipo P cb 04995421!, designado por J. Reveal, Harvard Pap. Bot. 9 (1): 148 (2004), isolectotipo F cb 0360581F!).

Chorizanthe tenuis Phil., Linnaea 33: 227. 1864-65? TIPO: "In collibus Serena" C. Gay 1915, 1836 (lectotipo, SGO 47989!, designado por Reveal, Harvard Pap. Bot. (1):151, 2004).

Chorizanthe humilis Phil. Anales Univ. Chile 91: 495.1895. TIPO: "Prope portum Coquimbo Novembri 1878 inveni" (holotipo, SGO 47962!).

Chorizanthe parviflora Phil., Anales Univ. Chile 91: 494. 1895. TIPO: "Habitat prope La Serena" (lectotipo, SGO 47991! designado aquí; isolectotipos, B cb 100525727!, F cb 18422!, SGO 38677!, SGO 95819!).

Chorizanthe pauciflora Phil. Anales Univ. Chile 91:496. 1895. "In monte Frai Jorge dicto et ad ostium fluminis Limari invenit, F. Philippi s.n." TIPO: posiblemente extraviado.

Subarbustos ramosos con tallos tendidos, rara vez procumbentes o ascendentes, de $5-40 \mathrm{~cm}$ de largo, los nuevos densa y largamente pilosos, los viejos, glabros; nudos cubiertos por las vainas persistentes. Hojas caulinares alternas, vaina del largo del nudo, margen ciliado; lámina pilosa, linear-lanceolada, de 1-2,5 x 0,1-0,3 cm, entera, margen revoluto, muy levemente mucronada. Los dicasios forman un sinflorescencia poco ramificada, a veces con aspecto de umbela muy laxa, pedúnculo basal de 1,5$2,5 \mathrm{~cm}$, ramificado en dos; brácteas en verticilos de dos, hirsutas, margen ciliado, lámina linear, de 0,3-0,4 x 0,1 cm, mucronadas; bractéolas en verticilos de tres, margen ciliado, aovadas, de 1-2,5 $\mathrm{mm}$ de largo, mucronadas. Involucro marrón, casi glabro en las costillas y el interior glabro, de 4-5 $\mathrm{mm}$ de largo, con líneas transversales y oblicuas evidentes, los lóbulos terminados en apéndices uncinados, córneos, subiguales. Perigonio de cerca de $4 \mathrm{~mm}$ de largo, anillo de glándulas evidente casi glabro; perigonio con los tépalos blancos; estambres, nueve (Fig. 6).

DisTRIBUCIÓN GEOGRÁFICA

Crece desde Huasco, Región de Atacama, hasta el PN Fray Jorge en la Región de Coquimbo. 
OBSERVACIONES

En la carpeta del tipo de la especie (Cuming $\mathrm{n}^{\circ}$ 904, K), el ejemplar de la izquierda es el material de esta especie, los otros dos corresponden a Lastarriaea chilensis (centro) y a Chorizanthe frankenioides (derecha).

Los ejemplares se reconocen, generalmente, por sus tallos apenas leñosos, ascendentes u horizontales, de no más de $20 \mathrm{~cm}$ de altura. Es un taxón con una extensa distribución geográfica si se la compara con la de otras especies del género. Tiene una morfología variable tanto dentro como entre las poblaciones, así como, también, entre años según la variación del monto de las precipitaciones.

La variación morfológica de la especie se refleja en una abundante sinonimia: C. parviflora Phil. es una variación del tipo con mayor cantidad de pelos en las hojas y tallos, pero con la inflorescencia y las flores similares a $C$. glabrescens; la localidad de su tipo corresponde, además, a la misma del de C. glabrescens (Coquimbo). En este trabajo la hemos lectotipificado puesto que Reveal (2004) no designa un lectotipo habiendo tres ejemplares (sintipo).

C. humilis Phil., también de Coquimbo, debe ser incluido aquí por su morfología y por la correspondencia con la localidad del tipo; Reveal (2004) basado en la pilosidad de las hojas lo incluyó erradamente entre los sinónimos de $C$. dasyantha; si bien R.A. Philippi no menciona un colector, en una etiqueta pegada en la misma carpeta del tipo (SGO 47969), figura P. Ortega.

Se incluye en la sinonimia a $C$. tenuis, cuyo ejemplar tipo tampoco discrepa significativamente del de $C$. glabrescens; respecto de éste, Reveal (2004) propuso una lectotipificación, pero lo atribuyó erróneamente como sinónimo de $C$. dasyantha Phil. y a J. Gay como colector.
Respecto de C. pauciflora, Reveal (2004) la incluyó erróneamente entre los sinónimos de C. kingii y, debido a que no existía ningún ejemplar del tipo en SGO (Muñoz \& Pisano, 1947), la lectotipificó con un ejemplar del herbario ISC (Iowa State University) (Reveal 2004). En el marco de este trabajo se solicitó dicho lectotipo, pero aparentemente también se ha perdido. La descripción de R.A. Philippi respecto de los involucros glabros, similares a los de $C$. glabrescens y el examen de ejemplares en el PN Fray Jorge nos inducen a incluir a $C$. pauciflora en la sinonimia de $C$. glabrescens.

\section{Materiales estudiados}

CHILE, Región de Atacama, prov. Huasco, $20 \mathrm{~km}$ al norte de Vallenar, 11-X-1987, C. von Bohlen 467 (SGO). Huasco, 10 m s.n.m., 8-X-1966, C. Jiles, 4990 (CONC). Huasco: 10 km este, 08-X-1987, S. Teillier 929 (CONC, SGO). Aguada Tongoy, camino a Los Bronces, 138 m s.n.m., 6-XII-2004, P. Baxter, M.F. Gardner, P. Hechenleitner, P.I. Thomas \& C. Zamorano (CONC, 176643; SGO 163180). Región de Coquimbo, prov. Elqui, Los Choros, 215 m s.n.m., 12-XI2001, C. Aedo 6861 (CONC). El Tofo, 350 m s.n.m., 20IX-1961, F. Schlegel 3902 (CONC). Cuesta Buenos Aires, minerales de El Tofo, 2-XI-1948, F. Behn s/n (CONC 8589). Carretera Panamericana, llanos frente a El Tofo, 350 m s.n.m., 21-X-1971, C. Marticorena, R. Rodríguez \& E. Weldt 1640 (CONC). Camino a Chungungo, $125 \mathrm{~m}$ s.n.m., 17/XI/2016, S. Teillier, J. Macaya, P. Novoa \& O. Fernández 8199 (CONC). Cuesta de Buenos Aires, ruta 5, $2 \mathrm{~km}$ N de Los Hornos, 280 m s.n.m., 5-XI-2006, E.J. Tepe, A. Marticorena \& P.B. Pelser 1773 (CONC). Cuesta Porotos, casi $20 \mathrm{~km} \mathrm{~N}$ de La Serena, 20-50 m s.n.m., 3-XII-

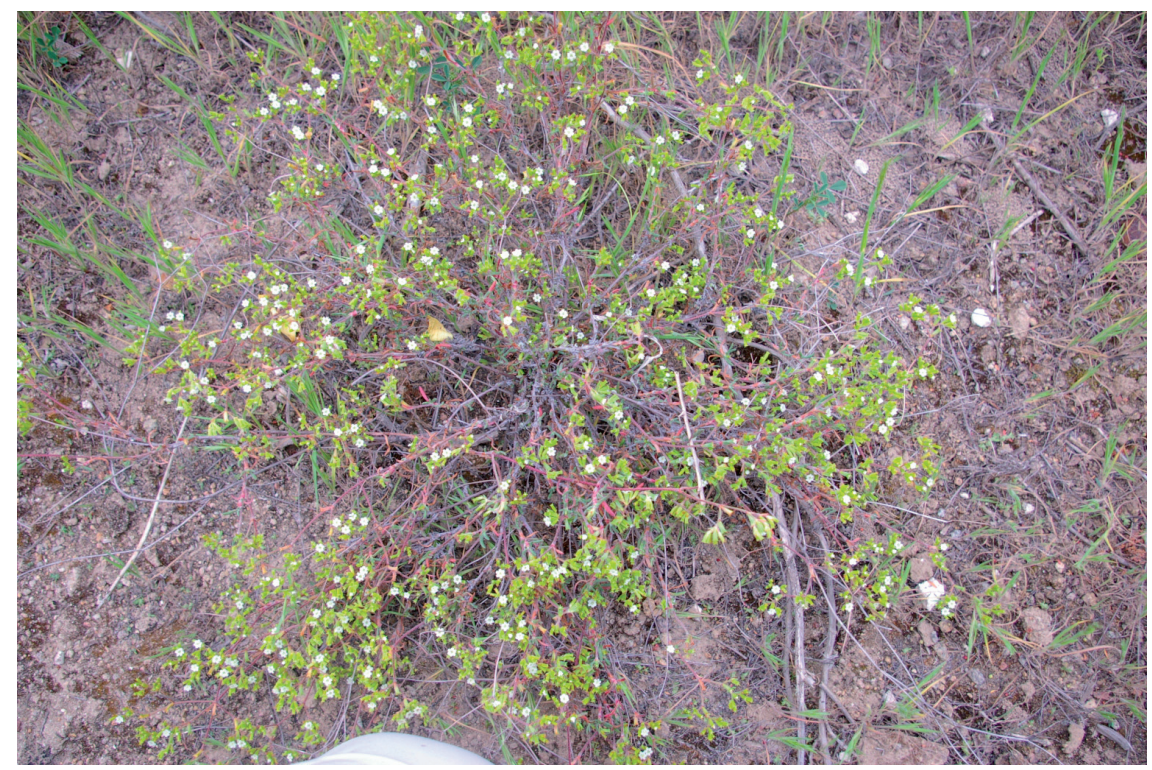

Figura 6. Chorizanthe glabrescens, hábito de una planta florecida. Camino a Chungungo, Región de Coquimbo. Fotografía de S. Teillier. / Chorizanthe glabrescens, habit of a flowering plant. Road to Chungungo, Región de Coquimbo. Fotografía de S. Teillier. 
1987, L.R. Landrum \& S.S. Landrum 5658 (CONC). Punta Arrayán, ca. 20 km of La Serena, 140-150 m s.n.m., 23-IX1988, M.O. Dillon, D. Dillon \& V. Poblete 5433 (F). Cuesta Porotitos ca. $15 \mathrm{~km} \mathrm{~N}$ of La Serena, ca. $170 \mathrm{~m}$ alt. 2-XII1987, M.O. Dillon \& S. Teillier 4997 (F). Cuesta Porotitos, 170 m s.n.m., 17-XI-2016, S. Teillier, J. Macaya, P. Novoa \& O. Fernández 8198 (CONC). Punta Teatinos, 20-IX1975, O. Zollner 9017 (CONC). La Serena, 22-I-1883, R.A. Philippi (SGO 95819). Cerros costeros al norte de La Serena, 110 m, 02-XI-2010, L. Landrum 11515 (SGO). Coquimbo, VII-VIII-1856, W. Harvey (E00514678). Punta Herradura, 50 m s.n.m., 31-X-1990, T.G. Lammers, C.M. Baeza, P. Peñailillo, 7654 (CONC). La Herradura, 115 m s.n.m., 16-XI-2016, S. Teillier, J. Macaya, P. Novoa \& O. Fernández 8197 (SGO, CONC). Prov. Limarí, camino a Fray Jorge, km 1 desde ruta 5, $200 \mathrm{~m}$ s.n.m., J. Tepe, A. Marticorena \& P.B. Pelser 1733 (CONC). Fray Jorge, cerro al oriente, 180 m s.n.m., 9-VIII-1948, C. Jiles 690 (CONC). Parque nacional Fray Jorge, 300 m s.n.m., 5-XI-1974, C. Marticorena, O. Matthei \& R. Rodríguez, 429 (CONC). Parque nacional Fray Jorge, orilla del bosque, 480 m s.n.m., 28-XI-1980, R. Rodríguez \& C. Marticorena 1681 (CONC). Entrada al parque nacional Fray Jorge, 29-X-1981, I. Meza \& C.Villagrán 1018 (SGO). Parque nacional Fray Jorge, 250 m s.n.m., 15-XI-2016, S. Teillier, J. Macaya, P. Novoa \& O. Fernández 8189 (CONC, SGO).

I.6. Chorizanthe kingii Phil., Anales Univ. Chile 43: 536. 1873. TIPO: Carrizal Bajo, Atacama, Chile. Thomas King s.n. (sin fecha). (Lectotipo: SGO 47948! designado aquí; isolectotipos SGO 38679! F18442!).

Chorizanthe deserticola Phil., Anales Univ. Chile 91: 498.
1895. TIPO: "habitat ad Breas in deserto Atacama, $A$. Larrañaga 1888" (holotipo, SGO 47990!).

Chorizanthe intricata Phil., Anales Univ. Chile 91:495. 1895. TIPO: "Loco dicto Canto del Agua in valle Carrizal invenit F. Philippi" (holotipo, SGO 47972!).

Chorizanthe tenuis Phil., Anales Univ. Chile. 91:499. 1895. TIPO: "Ad Vallenar legit orn. Belisarius Rojas" (holotipo, SGO 47967!).

Subarbustos ramosos, a veces, laxamente pulvinados; tallos floríferos erectos o decumbentes, leñosos, de (5)-10$40(50) \mathrm{cm}$ largo, rara vez mayores, poco ramificados; tallos nuevos pilosos, los viejos glabros. Hojas algo suculentas, glabras a escasamente pilosas, las caulinares con una vaina anular, estrecha, lámina linear-lanceolada, de 0,2$2,5 \times 0,1-0,3 \mathrm{~cm}$, entera y aguda. Los dicasios forman una sinflorescencia terminal similar a una umbela, pedúnculo basal de 0,5-5 (10) cm, con dos ramas de la misma o distinto largo, cada una con 3-6 flores; brácteas dispuestas en pares, lineares, de 0,3-0,4 x 0,1 cm, agudas; bractéolas también en pares, aovadas, de $2-2,5 \mathrm{~mm}$ de largo, fuertemente mucronadas. Involucro maduro color marrón, glabro, de 3-5 mm de largo, reticulado; los lóbulos terminados en un apéndice fuertemente uncinado. Perigonio de 1,5-3 $\mathrm{mm}$ de largo, anillo de glándulas evidente, casi glabro; perigonio con los tépalos blancos; estambres, seis o nueve. Aquenio con tres nervios bien marcados, de 2-2,5 mm (Fig. 7).

DisTRIBUCIÓN GEOGRÁFICA

Se encuentra desde la Región de Antofagasta, provincia de Antofagasta, hasta la Región de Coquimbo, provincia de Elqui, zona de El Tofo.

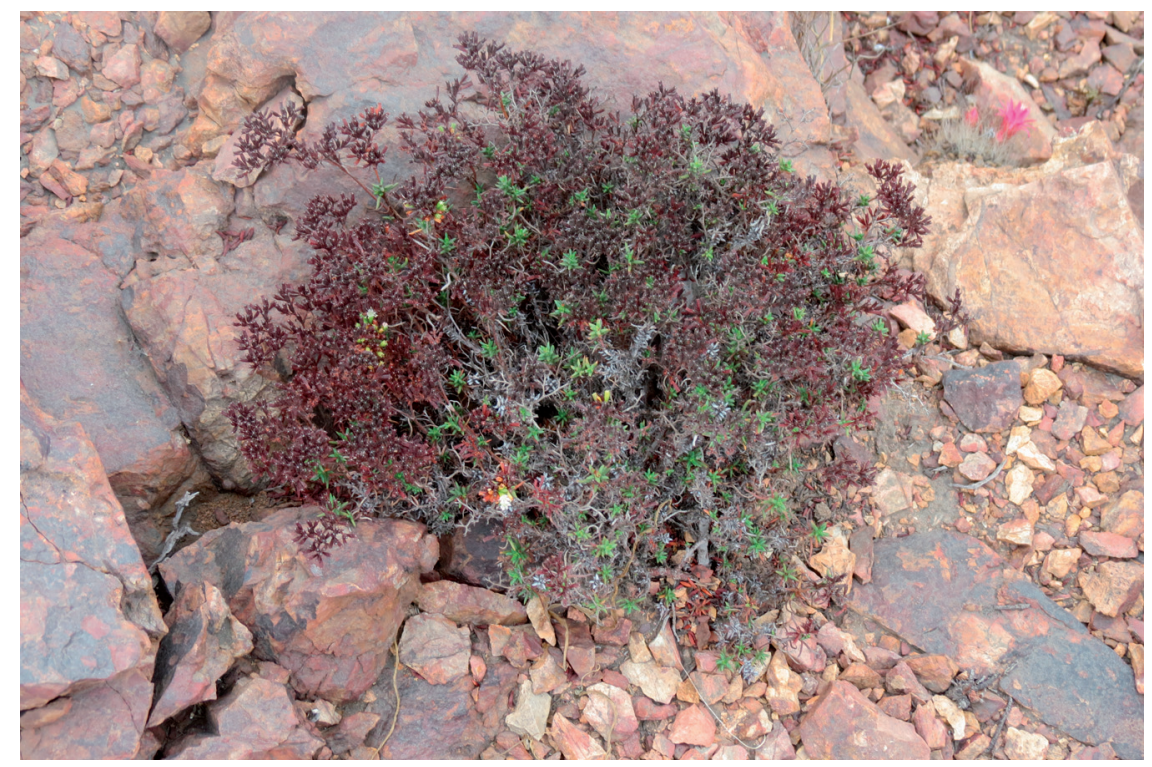

Figura 7. Chorizanthe kingii, hábito de una planta. Huasco, Región de Atacama. Fotografía de R. Lund. / Chorizanthe kingii, plant habit. Huasco, Región de Atacama. Photo: R. Lund. 
OBSERVACIONES

No es posible distinguir $C$. kingii de $C$. deserticola Phil. La mayor parte de las muestras estudiadas desde la localidad de Paposo hasta la de la cuesta de Pajonales, muestran una similitud general entre ellas, las variaciones que se observan en el hábito, en la forma de las hojas o en el tamaño del involucro, no se asocian a un territorio. Sin duda este es un taxón complejo que merece un mayor estudio in situ. El tipo de $C$. kingii incluso parece ser una variación extrema con las ramas de la inflorescencia muy abiertas y desiguales, las que generan una inflorescencia tipo cima escorpioide con los pedúnculos y pedicelos quebradizos, caracteres que se vuelven a encontrar en $C$. intrincata Phil., C. tenuis Phil. (1895) y C. stricta Phil. (in sched) descritos sobre la base de materiales recolectados en la zona de Vallenar.

C. kingii se ha lectotipificado con un ejemplar de SGO que es parte de la colección de T. King y tiene la planta más completa; Reveal (2004) señala que el ejemplar King s.n. es un holotipo, pero no reparó en que existen dos carpetas con números diferentes del mismo tipo en SGO. El tipo de C. intricata Phil. fue incorrectamente atribuido por Reveal (2004) a C. dasyantha. El tipo de C. tenuis Phil. de 1895, no de 1864-65, tiene una etiqueta donde está escrito " $C$. stricta Phil." y fue atribuido equivocadamente por Reveal (1989) a C. glabrescens. C. stricta nunca fue descrita por Philippi, pero a juzgar por los datos de la etiqueta del ejemplar aludido: "Vallenar, B. Rojas, febrero 1883", debe ser el mismo que sirvió de base para describir a $C$. tenuis Phil. (1895).

\section{Material estudiado}

CHILE, Región de Antofagasta, prov. Antofagasta, Paposo, quebrada Matancilla, 400 m s.n.m., 6-XI-1985, F. Schlegel 7910 (CONC). Paposo, quebrada de Matancilla, 185 m, 18-IX-1992, S. Teillier, P. Rundel \& P. García 2937 (SGO). Quebrada Las Tipias, X-1889, R.A. Philippi s/n (SGO 038662). Taltal, 09-IX-1938, R. López s/n (CONC 82630). Las Breas, IX-1938, R. López s/n (CONC 82637). Quebrada de la Vaca, NE del puerto de Taltal, 24-IX-1941, 500-560 m s.n.m., E. Pisano \& R. Bravo 193 (CONC, SGO). Taltal, quebrada El Nueve, 03-X-1953, M. Ricardi 2725 (CONC). Quebrada Septiembre, Taltal, 6-X-1954, M. Ricardi 3123 (CONC). Quebrada El Vetado, entre Taltal y caleta Cifuncho, 500 m, 29-IX-1941, E. Pisano \& R. Bravo 319 (SGO). Vecindad de Aguada Grande (Cachinal de la Costa de Philippi), cerca del límite provincial AntofagastaAtacama, ca. lat. 26 2'S. 16-18-XII-1925, I.M. Johnston 5777 (F). Región de Atacama, prov. Copiapó, $5 \mathrm{~km}$ al oeste de Totoral, 8-X-1991, C. Taylor, C. Von Bohlen \& A. Marticorena 10796 (CONC). Prov. Huasco, quebrada El Morado, entre Vallenar y Carrizalillo, 24-IX-1941, C. Muñoz \& G.T. Johnson 2029 (SGO). Huasco, 8-II-1959, C. Marticorena s/n (CONC 25387). Huasco, 10 m s.n.m., 19-
09-1966, G. Montero 7652 (CONC). Quebrada de Totoral (Boquerones), 160-180 m s.n.m., 24-XI-1941, E. Pisano \& R. Bravo, 791 (CONC, SGO). Quebrada de Carrizal, 9-X1987, S. Teillier 996 (CONC, SGO). Camino de Carrizal Bajo a Totoralillo, 27-XI-2008, R. Baines, M. Gardner, P. Hechenleitner, C. Morter \& D. Rae 142 (CONC). Vallenar, alrededores de la quebrada El Jilguero, 11-XI-1956, M. Ricardi \& C. Marticorena 3876 (CONC). $15 \mathrm{~km}$ al sur de Vallenar, 09-1952, L. E. Peña s/n (SQF 3388). Quebrada Chañaral, camino de Chañaral de Aceituno a Domeyko, 500 m s.n.m., 18-XI-2016, S. Teillier, J. Macaya, P. Novoa \& O. Fernández 8208 (CONC, SGO). Cuesta de Pajonales, 1150 m s.n.m., 31-X-1991, R. Rodríguez 2773 (CONC). Cuesta Pajonales, 1080 m s.n.m., 20-XI-2016, S. Teillier, J. Macaya, P. Novoa \& O. Fernández 8213 (CONC). Región de Coquimbo, prov. Elqui, Los Choros, 10 m s.n.m., 21-IX1975, O. Zollner 8326 (CONC). Carretera Panamericana, cerros frente a El Tofo, 14-X-1973, C. Marticorena \& O. Matthei, 213 (CONC). Frente a El Tofo, 450 m s.n.m., 18II-1966, M. Ricardi, C. Marticorena \& O. Matthei, 1695 (CONC). El Molle, 350 m s.n.m., 5-X-1966, C. Jiles 4912 (CONC). Llanos de El Tofo, 17-XI-1961, C. Jiles 3932 (CONC).

I.7. Chorizanthe limariensis Teillier et Macaya nov. sp. TIPO: Chile, Región de Coquimbo, prov. Limarí, camino a la desembocadura del río Limarí, 3047'22.04'S-71³7'47.97'O, 230 m s.n.m., 15-XI-2016, S. Teillier, J. Macaya, P. Novoa \& O. Fernández 8188 (holotipo, CONC!; isotipos SGO!, JBN!).

Pulvinate subshrubs, similar to $\mathrm{C}$. vaginata Benth., but differing having more densely imbricate leaves approaching rosettes, and leaves with narrowly linear-lanceolate blades, 7-10 mm long, (1-)2-3 mm wide.

Subarbustos, densa o laxamente pulvinados, tallos aéreos leñosos. Tallos erectos, salvo en los ejemplares más laxos donde son postrados, los viejos variando desde castaño a negro, con muchas cicatrices. Hojas muy densas en la parte aérea, prácticamente en rosetas, con tricomas largos, blancos, pero de color verde en ambas caras; vaina del largo del nudo, pilosa con el borde oblicuo y ciliado; lámina estrechamente linear- lanceolada, de 7-10 x (1) 2-3 mm, margen revoluto. Los dicasios, una a dos veces ramificados, forman una sinflorescencia umbeliforme; pedúnculo de 0,5$2 \mathrm{~cm}$, salvo en las formas laxas donde pueden alcanzar hasta $10 \mathrm{~cm}$. Brácteas foliáceas de a tres por verticilo, con el ápice mucronado; bractéolas dispuestas de a pares, pilosas, como las brácteas, de 2-3 mm de largo. Involucro verde, piloso, retículo poco evidente, de 4-7 mm de largo, lóbulos apicales desiguales y uncinados. Perigonio con tépalos pilosos en la cara externa, de 5-6 mm, blancos; anillo glandular apenas evidente; androceo con nueve estambres. Fruto, un aquenio encerrado en el perigonio esclerificado (Figs. 8 y 9). 
DiSTRIBUCIÓN GEOGRÁFICA

Se encuentra en localidades del litoral de la Región de Coquimbo, en la provincia de Limarí, desde la ribera sur del río Limarí hasta la caleta Manso.

\section{Observaciones}

Especie afín a $C$. vaginata, que crece en las dunas de más al sur del país. Se diferencia, principalmente, por la forma de las hojas, lineares en esta especie y romboidales hasta lanceoladas en $C$. vaginata.

C. limariensis es una especie compleja por la variación del hábito; normalmente forma cojines achaparrados con las hojas en rosetas muy apretadas, con las flores en inflorescencias terminales, sin embargo, algunos ejemplares emiten largos tallos floríferos laterales, postrados.
Este hábito típico se observa a lo largo del camino a la desembocadura del río Limarí; en la desembocadura misma, se observaron ejemplares más laxamente ramificados pero con los tallos postrados que podrían constituir una "forma" distinta. Otra "forma" podría constituir la población de caleta Sierra, donde las hojas llegan a ser glabras. Desde un punto de vista ecológico, crece con más frecuencia en las dunas consolidadas.

\section{Material estudiado}

CHILE, Región de Coquimbo, prov. Limarí. Fray Jorge, 400 m s.n.m., XI-1925, E. Werdermann 902 (SGO). Fray Jorge, IX-1934, C. Grandjot 386 (SGO). Fray Jorge, cerros, 21-IX-1952, M. Ricardi 2145 (CONC). Parque nacional Fray Jorge, acantilados, 17-9-1960, J. Saa s/n. (CONC).

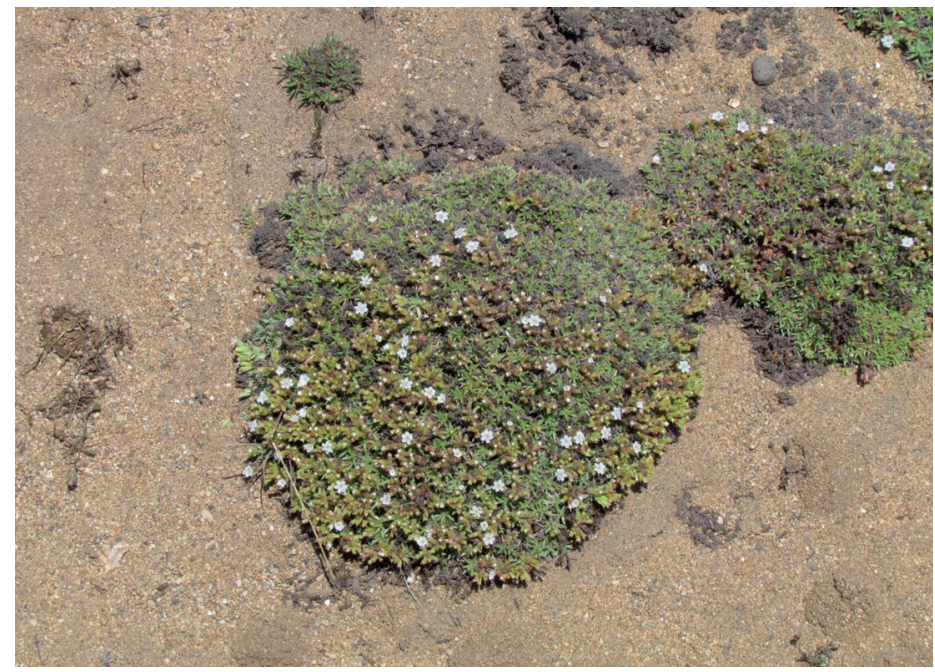

Figura 8. Chorizanthe limariensis, hábito de una planta pulvinada. Camino a la caleta Toro en la desembocadura del Limarí, Región de Coquimbo. Fotografía de S. Teillier. / Chorizanthe limariensis, a pulvinate plant. Road to Caleta Toro, Limari valley, Región de Coquimbo. Photo: S. Teillier.

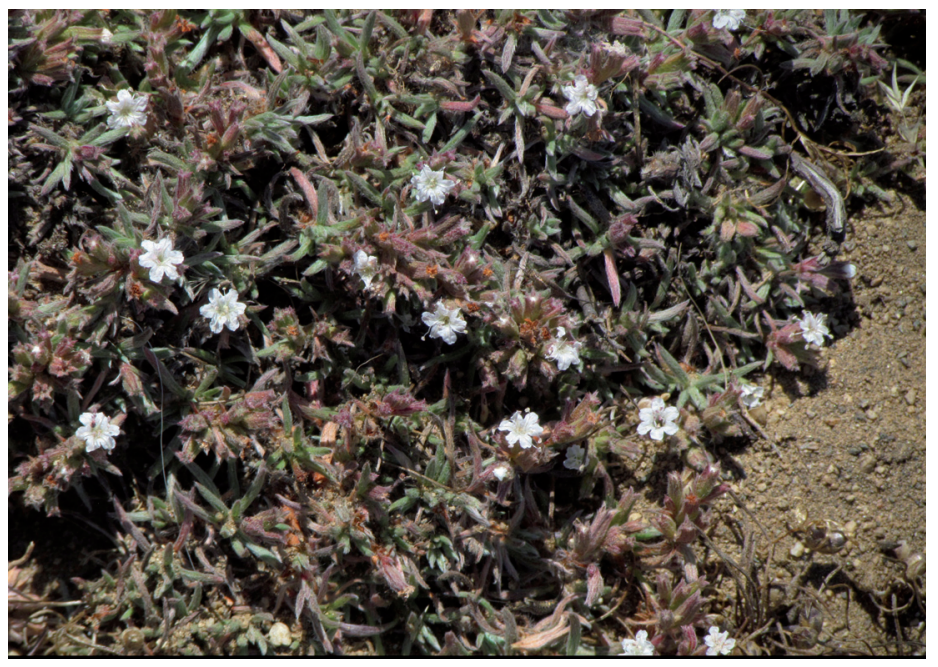

Figura 9. Chorizanthe limariensis, detalle de las hojas y las flores. Camino a la caleta Toro en la desembocadura del Limarí, Región de Coquimbo. Fotografía de S. Teillier. / Chorizanthe limariensis, leafs and flowers detail. Road to Caleta Toro, Limarí, valley, Región de Coquimbo. Photo: S. Teillier. 
Norte del puente Limarí, 9-IV-1962, L.E. Navas 2833 (CONC). Bosque de Talinay, lado sur de la desembocadura del Limarí, 500 m s.n.m., 18-21-XI-1940, C. Muñoz \& A. Coronel 1288 (SGO). Faldeos del cerro Talinay, 15-9-1957, M. Ricardi \& C. Marticorena 4297/ 682 (CONC). Faldeos del cerro Talinay, 15-9-1957, M. Ricardi \& C. Marticorena 4280/665 (CONC). 2,5 km al este de la desembocadura del río Limarí, 10 m s.n.m., 15-XI-2016, S. Teillier, J. Macaya, P. Novoa \& O. Fernández 8191(CONC, SGO). 2,5 km al este de la desembocadura del río Limarí, 10 m s.n.m., 15XI-2016, S. Teillier, J. Macaya, P. Novoa \& O. Fernández 8191-A (CONC, SGO). Peñablanca, ruta 5 Norte, $50 \mathrm{~m}$ s.n.m., 20-XI-2016, S. Teillier, J. Macaya, P. Novoa \& O. Fernández 8214 (CONC, SGO). Peñablanca, ruta 5 Norte, 50 m s.n.m., 20-XI-2016, S. Teillier, J. Macaya, P. Novoa \& O. Fernández 8215 (CONC, SGO). Caleta La Cebada, 10 m s.n.m., 20-XI-2016, S. Teillier, J. Macaya, P. Novoa \& O. Fernández 8216 (CONC, SGO). Caleta Manso, 9 km al norte de Huentelauquén, 20 m s.n.m., 31-X-2000, S. Teillier \& C. Márquez 4894 (CONC).

I.8. Chorizanthe macraei Benth., Trans. Linn. Soc. London 17 (3): 417. 1836. TIPO: Macrae, Coquimbo, Chili (holotipo, K cb 000532025!, isotipos F cb 0360582F!, G cb 00437267!).

C. macraei Benth. var. humilis Benth in A. DC., Prodr. 14(1): 24. 1856. TIPO: [Chile] "Ad Coquimbo", C. Gay s.n. (Reveal, 2004 señala que hay un holotipo en G-DC, pero no esté disponible en la web).

Subarbustos leñosos, de $5-20 \mathrm{~cm}$ de altura. Tallos erguidos, los nuevos hirsutos a densamente lanosos. Hojas con vaina muy breve, anular, lámina densamente gris-pilosa en ambas caras, linear, de 1,5-2,5 x 0,1-0,2 cm, aguda o apenas mucronada. Los dicasios forman una sinflorescencia, glomeruliforme, umbeliforme o, raras veces, una panoja; pedúnculo de 4-11 cm de largo, solitario, ramificado hacia el ápice en 3-4 ramificaciones muy breves. Brácteas en verticilos de tres, densamente pilosas, lanceolada, de 0,4$0,5 \times 0,2 \mathrm{~cm}$, mucronada; bractéolas con base concrescente, dispuestas en verticilos de a dos, similares a las brácteas, pero menores. Involucro desde densamente velloso, de 5-6 mm de largo, retículo poco evidente, cubierto por los tricomas, apéndice notorio, pero poco uncinado. Perigonio de $4 \mathrm{~mm}$ de largo, tépalos blancos, escasamente pilosos en la parte externa, glándulas del tubo presentes, glabras; androceo con nueve estambres.

\section{DisTRIBUCIÓN GEOGRÁFICA}

Se ha recolectado en las regiones de Atacama y Coquimbo, desde Cachiyuyo hasta Andacollo, en localidades del interior.

\section{OBSERVACIONES}

Esta es una de las primeras especies descritas de Chorizanthe. Los ejemplares tipo y los isotipos disponibles no muestran de buena forma la morfología y la variación de la especie, particularmente la estructura de la inflorescencia y de las flores. Definir las relaciones de C. macraei con C. umbellata Phil., C. viridis Phil. y C. rosasii Teillier $\&$ Macaya requiere, sin duda, un esfuerzo mayor de exploración y de trabajo de campo.

En el pliego K cb 000532025 del Herbarium Benthamianum (1854) hay dos ejemplares distintos, el holotipo de C. macraei corresponde al primero de izquierda a derecha, el otro corresponde a C. ramosissima (sinónimo de C. paniculata). En Ginebra existe un isotipo de Macrae $\left(\mathrm{N}^{\circ} 46\right)$ etiquetado por ¿Bentham? como C. ramosissima Benth.

Reveal (2004) influido por las etiquetas del holotipo y del isotipo lo pasó erradamente a la sinonimia de $C$. paniculata. Existen ejemplares como por ejemplo los de la quebrada San Carlos (prov. Elqui) (Villagrán \& Torres $\mathrm{s} / \mathrm{n}, \mathrm{CONC}, \mathrm{SGO}$ ) que coinciden muy bien con el tipo de C. macraei coleccionado por J. Macrae que sirvió para la descripción original de la especie.

\section{Material estudiado}

CHILE, Región de Atacama, prov. Huasco, camino a la mina Los Cristales por quebrada El Carbón, $\mathrm{km}$ 7, $1350 \mathrm{~m}$ s.n.m., 21-X-1971, C. Marticorena, R. Rodríguez \& Weldt 1711(CONC). Región de Coquimbo, prov. Elqui, quebrada Chanchoquí, 1000 m s.n.m., 5-X-1948, F. Behn s/n (CONC 23342). Quebrada San Carlos, XII-1974, R. Torres \& C. Villagrán s/n (CONC 82665; SGO 126622). Quebrada San Carlos, $5 \mathrm{~km}$ al oeste de Vicuña, pies del cerro Tololo, 600800 m, 12-VIII-1975, C. Villagrán, R. Torres \& R. Osorio s/n (SGO 126393). Paihuano, 1884, F. Peralta s/n (SGO 047985). La Serena, X-1878, F. Philippi s/n. (SGO 038659). Cuesta de La Viñita, interior de Marquesa, parte alta de la cuesta, 20-IX-1957, C. Muñoz 4211 (SGO). Cuesta de La Viñita, 17-X-1963, C. Marticorena \& O. Matthei 341 (CONC). Camino Vicuña-Río Hurtado, km 20,2 (Iglesia), 1650 m s.n.m., 19-I-1993, T. Stuessy \& E. Ruiz 12776 (CONC). Prov. Limarí, Andacollo, I-1836, C. Gay (SGO 48001). Andacollo, $5 \mathrm{~km}$ al S, 1100-1200 m s.n.m., 1 al 6-IV-2008, M. Mihoc 340 (CONC).

I.9. Chorizanthe mieresii Teillier \& Macaya, Novon 26: 40-44. 2018. TIPO. Chile, Región de Coquimbo, prov. Elqui: Choros Bajo, camino a punta de Choros, $29^{\circ} 17^{\prime} 11.58^{\prime}$ 'S-71'18'58.42”W, 55 m s.n.m., 17-XI-2016, S. Teillier, J. Macaya, P. Novoa \& O. Fernández 8200 (Holotipo CONC!; isotipo SGO).

Subarbustos leñosos, forman cojines densos o laxos, de hasta $25 \mathrm{~cm}$ de alto. Hojas algo carnosas, glabras; vainas bien desarrolladas, rojizas, con el margen ciliado; láminas de ámbito aovado-triangular, de 5 x $4 \mathrm{~mm}$, fuertemente revolutas, ápice fuertemente mucronado hasta pungente. Dicasios dos a tres veces ramificados, 
forman una sinflorescencia terminal, umbeliforme, densa; pedúnculo ausente o muy breve, brácteas idénticas a las hojas; bractéolas en pares, ciliadas en el margen de su vaina, de 2-3 mm de largo, con un mucrón fuerte de 1-1,5 $\mathrm{mm}$. Involucros de 5-7 $\mathrm{mm}$ de largo, verde-amarillentos a café rojizos a la madurez, casi glabros por fuera y pilosos en el interior; retículos evidentes, tanto por fuera como por dentro; apéndices de tamaño desigual, terminados en gancho. Perigonios de $4 \mathrm{~mm}$ de largo, glabros por fuera; tépalos blancos, rara vez rosados; anillo de glándulas glabro. Estambres 9 (Figs. 10 y 11).

DistRIBUCIÓN GEOGRÁFICA: Crece desde el litoral de la quebrada de Carrizal Bajo (Atacama) hasta la localidad de Choros Bajo (Coquimbo), incluyendo la isla Chañaral. Crece en las dunas consolidadas junto con otras especies psamófilas.

OBSERVACIONES: Ejemplares de herbario de esta especie se han determinado como C. frankenioides, de la que difiere por el hábito pulvinado y por las hojas más cortas y mucronadas. En el área norte de la distribución se observaron algunas poblaciones con hojas apenas mucronadas y perigonio rosado, pero sin duda se pueden incluir en esta especie. Difiere de C. vaginata Benth. y C. limariensis, las otras especies pulvinadas, por la forma de las hojas, crasas y apiculadas. A veces crece en simpatría con $C$. kingii, de la que se distingue por sus hojas más cortas y fuertemente mucronadas.

En SGO existe un ejemplar recolectado por F. Philippi (28-X-1889), la etiqueta señala como localidad a "Finca de Chañaral" que puede ser asignado a esta especie, esa localidad, sin embargo, no es parte del área de distribución geográfica de la especie, quizás se trate de un error por "isla"de Chañaral. Se consigna la observación por ser el ejemplar más antiguo de la especie que existe en los herbarios consultados.

Se la protege solo en el parque nacional Llanos de Challe, ubicado en la costa de la Región de Atacama. De acuerdo con los criterios de UICN (2012) correspondería clasificarla como "en peligro de extinción" pues los ambientes en los que crece están siendo progresivamente urbanizados u ocupados por la industria portuaria y minera.

\section{Material estudiado}

CHILE, Región de Atacama, prov. Huasco, Carrizal Bajo, T. King s/n. (SGO 038675). Quebrada Carrizal Bajo, 17IX-1957, M. Ricardi \& C. Marticorena 4421/826 (CONC). Camino costero, $3 \mathrm{~km}$ antes de la entrada al PN Llanos de Challe, 20 m s.n.m., 19-XI-2016, S. Teillier, J. Macaya, P. Novoa \& O. Fernández 8212 (CONC). Punta de Lobos, camino costero, al $\mathrm{N}$ de Huasco, 115 m s.n.m., 19-XI2016, S. Teillier, J. Macaya, P. Novoa \& O. Fernández 8211 (CONC). Tres Playitas, $16 \mathrm{~km}$ norte de Huasco, 4 m s.n.m., 19-XI-2016, S. Teillier, J. Macaya, P. Novoa \& O. Fernández 8210 (CONC, SGO). Huasco, 26-XII1971, K. Beckett, M. Cheese \& J. Watson 4708 (SGO). Huasco, detrás de la planta termoeléctrica Guacolda, $30 \mathrm{~m}$ s.n.m., 19-XI-2016, S. Teillier, J. Macaya, P. Novoa \& O. Fernández 8209 (CONC, SGO). Las Lozas, 15-VII-2011, G. Mieres s/n (CONC 180039). Los Bronces, 26-X-1984, M. Muñoz 2005 (SGO). El Hinojo, camino a Domeyko, 260 m s.n.m., 18-XI-2016, S. Teillier, J. Macaya, P. Novoa \& O. Fernández 8206 (CONC, SGO). Caleta Carrizalillo, 95 m s.n.m., 18-XI-2016, S. Teillier, J. Macaya, P. Novoa \& O. Fernández 8205 (CONC, SGO). Caleta Chañaral de Aceituno, 3 m s.n.m., 18-XI-2016, S. Teillier, J. Macaya, P. Novoa \& O. Fernández 8204 (CONC, SGO). Isla Chañaral,

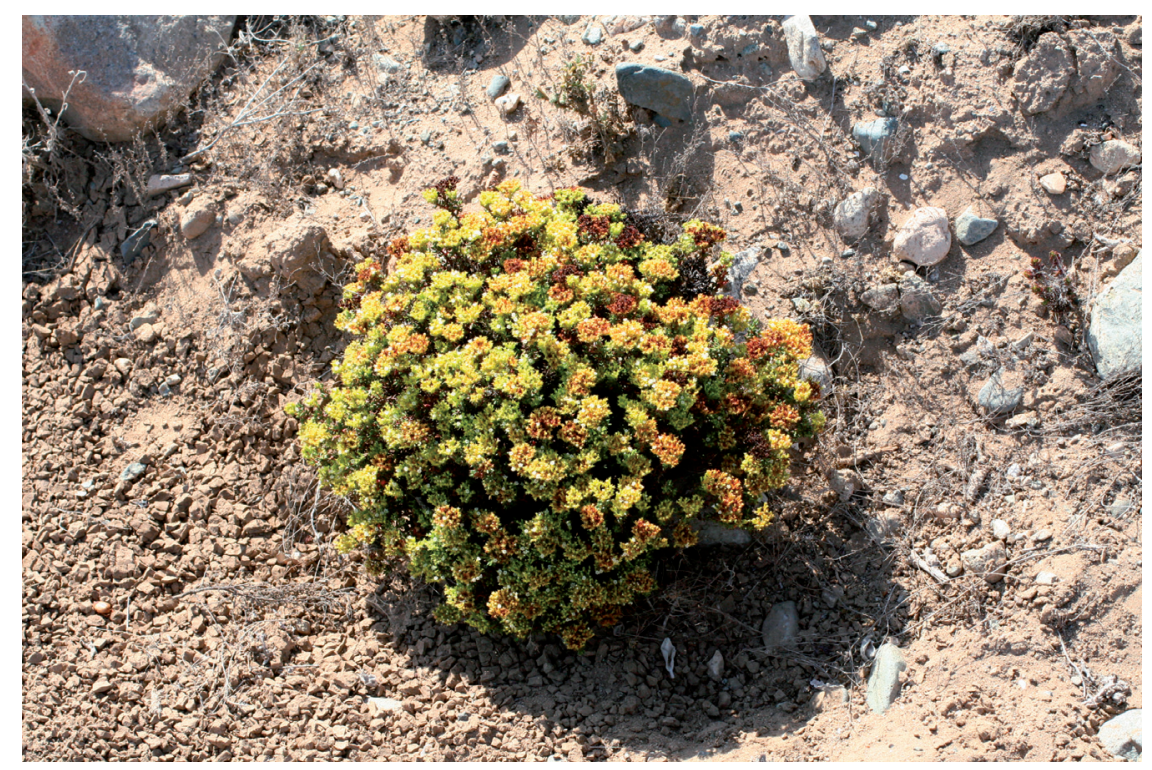

Figura 10. Chorizanthe mieresii, hábito. Caleta Chañaral de Aceituno, Región de Coquimbo. Fotografía de S. Teillier. / Chorizanthe mieresii, habit. Caleta Chañaral de Aceituno, Región de Coquimbo. Photo: S. Teillier. 
156 m s.n.m., 17-XI-2002, G. Arancio 15039 (CONC). Camino de Punta Choros a Chañaral de Aceituno, $30 \mathrm{~m}$ s.n.m., 18-XI-2016, S. Teillier, J. Macaya, P. Novoa \& O. Fernández 8203 (CONC). Región de Coquimbo, prov. Elqui, punta de Choros, 30 m s.n.m., 17-XI-2016, S. Teillier, J. Macaya, P. Novoa \& O. Fernández 8202 (CONC). Entre Choros Bajo y punta de Choros, $29^{\circ} 17^{\prime}$ S- $71^{\circ} 21^{\prime} \mathrm{W}, 17-\mathrm{XI}-$ 2016, S. Teillier, J. Macaya, P. Novoa \& O. Fernández 8201 (CONC, SGO).

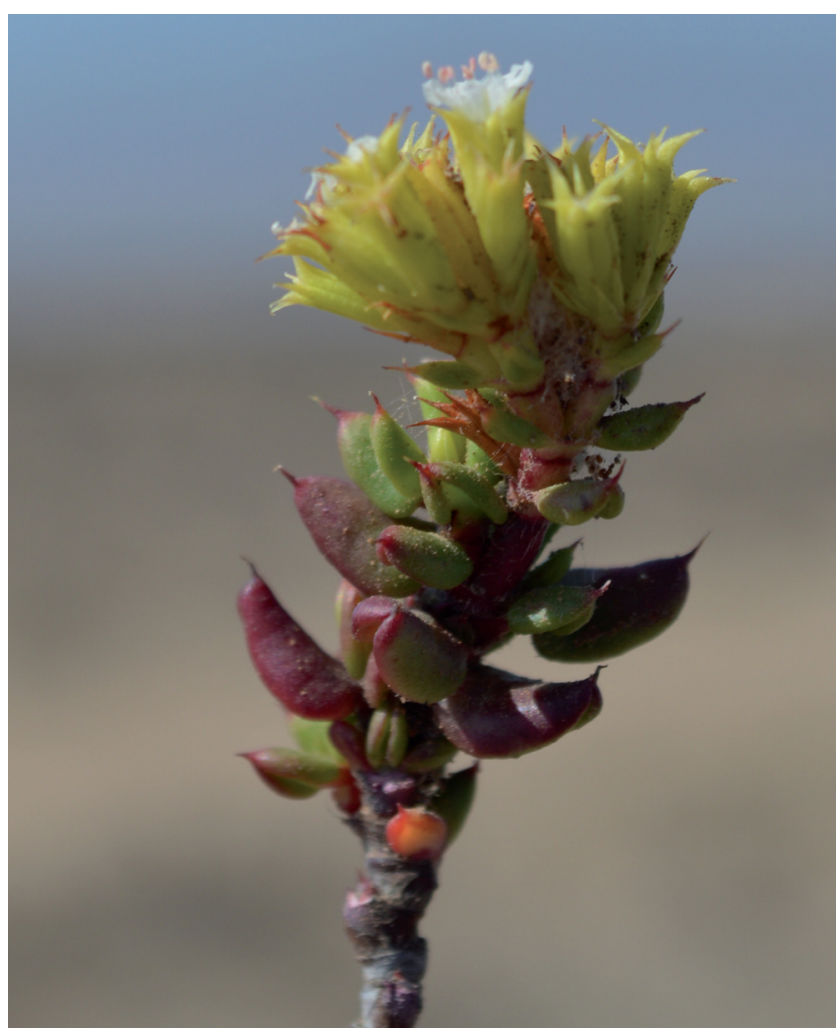

FIgURA 11. Chorizanthe mieresii, detalle de una rama mostrando las hojas mucronadas y las flores. Caleta Chañaral de Aceituno, Región de Coquimbo. Fotografía de J. Macaya. / Chorizanthe mieresii, a part of the stem showing mucronate leafs and the flowers. Caleta Chañaral de Aceituno, Región de Coquimbo. Photo: J. Macaya.

I.10 Chorizanthe navasiae Teillier \& Macaya, Novon 26: 44-48. 2018. TIPO: Chile. Región de Coquimbo, prov. Choapa, Corral de Julio, 31 ${ }^{\circ} 10^{\prime} \mathrm{S}-71^{\circ} 37^{\prime} \mathrm{W}, 280 \mathrm{~m}$ s.n.m. 27-XI-1971, C. Jiles 5860 (holotipo, CONC!).

Hierbas perennes, con rizomas; tallos floríferos no leñosos, horizontales a procumbentes, de $5-20 \mathrm{~cm}$. Hojas aglomeradas en la base de la planta; vainas más cortas que los nudos, ciliadas en el margen superior; láminas glabras a seríceovellosas en ambas caras, lineares, a linear-lanceoladas, de 15-20 x 0,5-2 mm, mucronadas, no punzantes. Los dicasios forman sinflorescencias terminales con aspecto de glomérulos densos, de 0,5-2 x 0,5-2 $\mathrm{cm}$ de diámetro o más laxos y algo abiertos; las ramificaciones secundarias y terciarias brevísimas; pedúnculos de $12-15 \mathrm{~cm}$ de largo, no ramificados; brácteas castaño-rojizas, seríceo-vellosas, lineal-lanceoladas, de 6-7 $\mathrm{mm}$ de largo, margen piloso y ápice agudo, muy próximas al glomérulo; bractéolas similares a las brácteas, de 4-6 mm de largo. Involucros de hasta $5 \mathrm{~mm}$ de largo, castaño-rojizos, seríceo-vellosos por la parte externa, con pelos más densos en las costillas; retículos con las líneas transversales apenas diferenciadas; apéndices uncinados, pilosos. Perigonios de $4 \mathrm{~mm}$ de largo, pilosos por fuera; anillo de glándulas piloso, tépalos blancos (Fig. 12).

\section{DisTRIBUCIÓN GEOGRÁFICA}

Endémica de la Región de Coquimbo, donde crece entre los valles de los ríos Limarí y Choapa, entre 5-280 m s.n.m. Se observó en laderas y taludes asoleados donde crecían cactus como Trichocereus skottsbergii Backeb., bromeliáceas como Puya alpestris (Poepp.) Gay subsp. zollneri (Mez) Zizka, J.V. Schneid. \& Novoa y Puya venusta Phil. y arbustos tales como Bahia ambrosioides Lag. (Asteraceae), Heliotropium stenophyllum Hook. et Arn. (Boraginaceae) y Oxalis gigantea Molina (Oxalidaceae).

\section{OBSERVACIONES}

Se observan plantas con hojas casi glabras hasta seríceovellosas; la forma, a su vez, varía, desde linear-lanceolada hasta linear. La inflorescencia varía incluso en la misma planta, desde una sinflorescencia esférica y densa hasta una algo desplegada y menos esférica.

Los ejemplares Teillier \& Márquez 4894 (CONC) y Jiles 1806 (CONC) se incluyeron erradamente entre los paratipos de C. navasiae (Teillier \& Macaya, 2018).

Dado que la especie tiene una distribución reducida a la franja litoral, y a no más de $40 \mathrm{~km}$ de largo, y que se trata de un sector con donde aún se pastorea con cabras y además se está instalando infraestructura (aerogeneradores, urbanización, carreteras), de acuerdo con los criterios UICN (2012), correspondería clasificarla como "en peligro".

\section{Material estudiado}

CHILE, Región de Coquimbo, prov. Choapa, caleta Sierra, 30 m s.n.m. 14-XI-2016, S. Teillier, J. Macaya, P. Novoa \& O. Fernández 8185 (CONC). Caleta Oscuro, 5-50 m s.n.m., 02-XI-1974, C. Marticorena, O. Matthei \& R. Rodríguez 28 (CONC). Corral de Julio, 150 m s.n.m., 6-XI-1976, M. Muñoz 920 (SGO). Quebrada El Teniente, $1 \mathrm{~km}$ al sur, $80 \mathrm{~m}$ s.n.m., 24-X-2006, M. Rosas 4063 (colección INIA-Intihuasi). Quebrada El Teniente, $2 \mathrm{~km}$ al sur. $31^{\circ} 00^{\prime} 41 \mathrm{~S}-71^{\circ} 36^{\prime} 40 \mathrm{~W}$, 220 m s.n.m., 28-X-2008. M. Rosas 5940 (colección INIAIntihuasi). Panamericana, $2 \mathrm{~km}$ sur del puente El Teniente, 215 m s.n.m., 14-XI-2016, S. Teillier, J. Macaya, P. Novoa \& O. Fernández 8186 (CONC). 


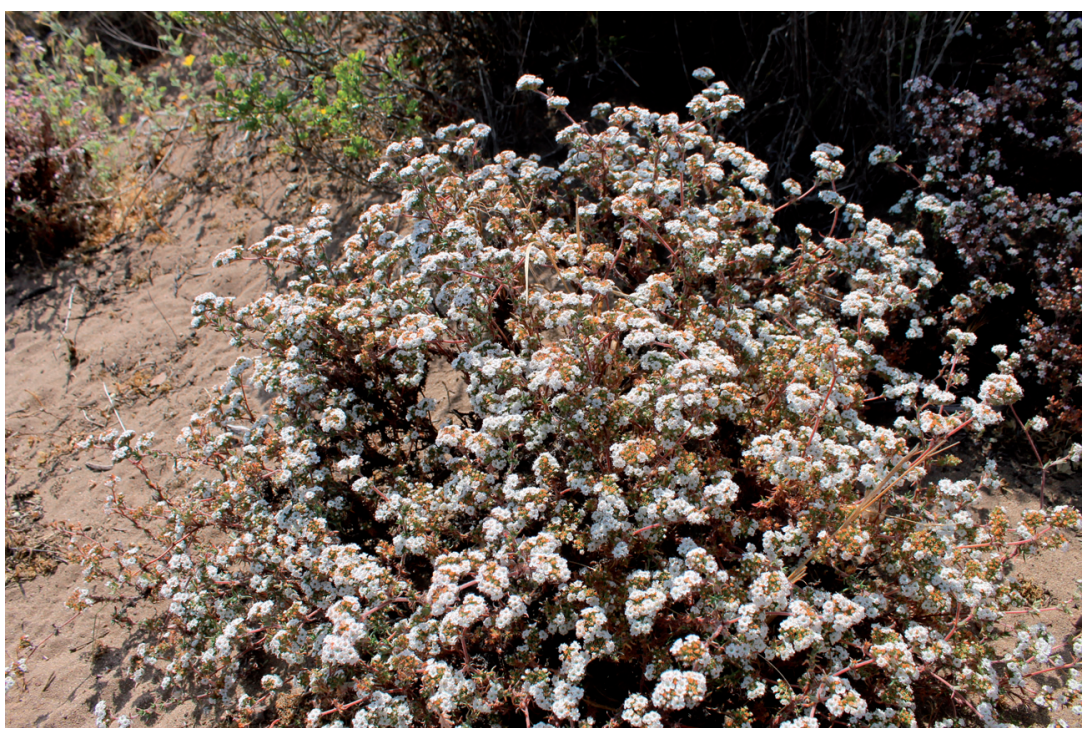

Figura 12. Chorizanthe navasiae, hábito de una planta excepcionalmente grande y florecida. Localidad de Cabrería, N de Los Vilos, Región de Coquimbo. Fotografía: P. Novoa. / Chorizanthe navasiae, habit of an exceptional big and flowering plant. Cabrería N of Los Vilos, Región de Coquimbo. Photo: P. Novoa.

I.11. Chorizanthe novoana Teillier \& Macaya, Novon 26: 48-50. 2018. TIPO. Chile, Región de Valparaíso, prov. Valparaíso, Laguna Verde, $33^{\circ} 04^{\prime} 16 \mathrm{~S}-71^{\circ} 39^{\prime} 32 \mathrm{~W}, 26-\mathrm{XI}-$ 2004, O. Fernández 105 (holotipo, JBN!; isotipo, CONC!). Hierbas perennes de aspecto cespitoso, provistas de un rizoma desde donde emergen los tallos floríferos, de hasta $15 \mathrm{~cm}$ de largo. Todas las hojas aglomeradas en la base, glabras o casi glabras, láminas lineares, de 20-25 x 0,5-1 $\mathrm{mm}$, con el ápice apenas mucronado. Los dicasios forman una sinflorescencia con el aspecto de una panícula muy ramificada y laxa; los pedúnculos alcanzan hasta $10 \mathrm{~cm}$ de largo y se bifurcan más arriba de las brácteas basales; bractéolas de color castaño-rojizo, de 5 x 1-1,5 mm, dispuestas de a dos por nudo, base del margen membranoso y ciliado, ápice largamente aristado. Involucros de hasta $6 \mathrm{~mm}$ de largo; castaño-rojizos, glabros, con retículo muy evidente; lóbulos terminados en un apéndice de 1-1,5 mm, fuertemente uncinados. Perigonios de $5 \mathrm{~mm}$ de largo, algo pilosos por fuera; anillo de glándulas, piloso, tépalos blancos (Fig. 13).

\section{DisTRIBUCIÓN GEOGRÁFICA}

Endémica de la Región de Valparaíso y conocida solo de la localidad de Laguna Verde, donde crece en los acantilados que enfrentan al mar.

\section{OBSERVACIONES}

Al parecer reducida a los acantilados costeros del sur del puerto de Valparaíso. Por tratarse de un área bajo fuerte presión antrópica y de acuerdo con los criterios UICN (2102), correspondería clasificarla como "en peligro crítico".

\section{Material estudiado}

CHILE, Región de Valparaíso, prov. Valparaíso, Laguna Verde, 2-XI-1990, T.G. Lammers, C.M. Baeza \& P. Peñailillo 7784 (CONC).

I.12. Chorizanthe paniculata Benth., Trans. Linn. Soc. London 17 (3): 417.1836.

TIPO: Andes of Chili, Cuming 249 (lectotipo, K cb 000532038, designado aquí, isolectotipos, BM cb 000993215!, E cb 00514671!, G cb 00437266!; asociados a Bridges 515, K cb 000532037 y K cb 000532038 ! erróneamente atribuido a Cuming).

Chorizanthe ramosissima Benth., Trans. Linn. Soc. London 17 (3): 417.1836.

TIPO: Collina, Chili, 1825, J. Macrae (holotipo, K cb 000532025 !).

Trigonocarpus secundiflorus Bert. ex Steud., Nomencl. Bot., ed. 2-2 (12-13): 710. 1841. TIPO: Rancagua, 01-011818, C. Bertero s.n. (holotipo, SGO 47971!)

Chorizanthe densa Phil., Anal. Univ. Chile 91: 496-499. 1895.

TIPO: "Prope oppidum Santa Rosa de los Andes in provincia Aconcagua inveni", R.A. Philippi (holotipo, SGO 47949!; isotipos, $\mathrm{K}$ cb 000532029!; B (destruido, foto en F0BN018417!).

Subarbustos, poco leñosos, de 20-30 cm de altura. Tallos erguidos o tendidos, los viejos frecuentemente en zigzag, glabros, los nuevos, seríceo-pubescentes. Hojas con vainas rudimentarias; láminas pilosas en ambas caras, lanceoladas, de 1-1,5 x 0,2 cm, algunas levemente mucronadas. Los dicasios forman una sinflorescencia con forma de panícula 
laxa o más o menos densa; pedúnculos de $4-5 \mathrm{~cm}$ de largo, ramificados en pares, raras veces en tres; brácteas en verticilos de tres, similares a las hojas de $0,5-0,7 \times 0,2 \mathrm{~cm}$ de largo, apenas mucronadas; bractéolas en verticilos de a tres, densamente pilosas, lanceoladas, de 1-3 mm de largo, levemente mucronadas. Involucro piloso, de $5 \mathrm{~mm}$ de largo, con el retículo marcado, lóbulos con el ápice uncinado. Perigonio de $4 \mathrm{~mm}$ de largo, tépalos blancos, pilosos en la parte externa, glándulas del tubo presentes, pilosas; androceo con nueve estambres.

\section{DisTRIBUCIÓN GEOGRÁFICA}

Especie endémica de Chile, se distribuye entre las regiones de Coquimbo, prov. de Choapa y de O'Higgins, prov. de Cachapoal. Crece en el interior, en ambiente montano (7501500 m s.n.m.).

\section{OBSERVACIONES}

Especie variable en cuanto a la estructura de la sinflorescencia, desde una panoja muy abierta ("C. ramosissima") hasta una panoja pseudoumbelada ("C $C$. densa").

Existen dos ejemplares mencionados en la descripción de Bentham (1836), Cuming 249 y Bridges 515, ambos de la cordillera de Chile, la tipificación ha sido muy compleja. Se buscó un lectotipo en las bases de datos de los herbarios, particularmente en Jstor Global Plants y en Kew Garden donde está depositado el material que sirvió para describir la especie y se encontraron varios ejemplares tipificados por J. Reveal como "isolectotipos", sin embargo, no se encontró ninguno etiquetado como "lectotipo". Como dato complementario, Reveal (2004) califica al ejemplar Cuming 249 en K como "holotipo", no como lectotipo. Como conclusión se resolvió tipificar al ejemplar "Cuming 249" del herbario K como lectotipo, y tanto a sus propias copias y como a Bridges 515 (y sus copias), como isolectotipos, tal como los dejó etiquetados J. Reveal.

Se tuvo acceso a la imagen del ejemplar de Macrae (K cb 000532025) del Herbarium Benthamianum (1854), en el pliego hay dos ejemplares distintos, el holotipo de $C$. ramosissima corresponde al segundo de izquierda a derecha.

\section{Materiales estudiados}

CHILE, Región de Coquimbo, prov. Choapa, "Choapa", 750 m s.n.m., IX-1964, M. Díaz s/n (CONC 82616). Región de Valparaíso, prov. Petorca, cerro Negro, Cabildo, $1500 \mathrm{~m}$ s.n.m., 10-III-1978, O. Zollner 10034 (CONC). Prov. San Felipe, santuario de la naturaleza "Serranía del Ciprés", cerro Tabaco, 2155 m s.n.m., 21-XII-2013, A. Madrid \& J. Larraín 242 (CONC). San Felipe, 11-X-1970, O. Zollner 4338 (CONC). Prov. Los Andes, camino de Los Andes a Portillo, km 13, 1200 m s.n.m., 15-XI-1970, C. Marticorena \& E. Weldt 536 (CONC). Río Colorado (Los Andes), 1000 m s.n.m., XII-1939, R. Milner s/n. (CONC 23335). Prov. Quillota, Quillota, G. Germain s/n. (SGO 047993). Cordillera de El Melón, La Ollita, 1957 m, 18-I-2011, A. Moreira 1438 (SGO). Región Metropolitana, prov. Chacabuco, baños de Colina, 28-III-1940, R. Milner s/n (CONC 2332). Termas de Colina, 21-XII-1961, Navas 2734 (SQF). Prov. Santiago, cajón del Arrayán, XII-1891, K. Reiche s/n (SGO 061779). Las Condes, III-1932, F. Jaffuel 3130 (CONC). Cerro Provincia, 1150 m s.n.m., 15-II-1967, F. Schlegel 5876 (CONC). Cerro San Cristóbal, XII-1858, R.A. Philippi s/n (SGO 047995). Quebrada de San Ramón (sic), 1400 m s.n.m., X-1950, V. Barros s/n (CONC 82633). Prov. Cordillera, Lagunillas, 7 y 8-I-1972, K. Beckett, M. Cheese \& J. Watson 4828 (SGO). Camino a Los Rodados, cajón del

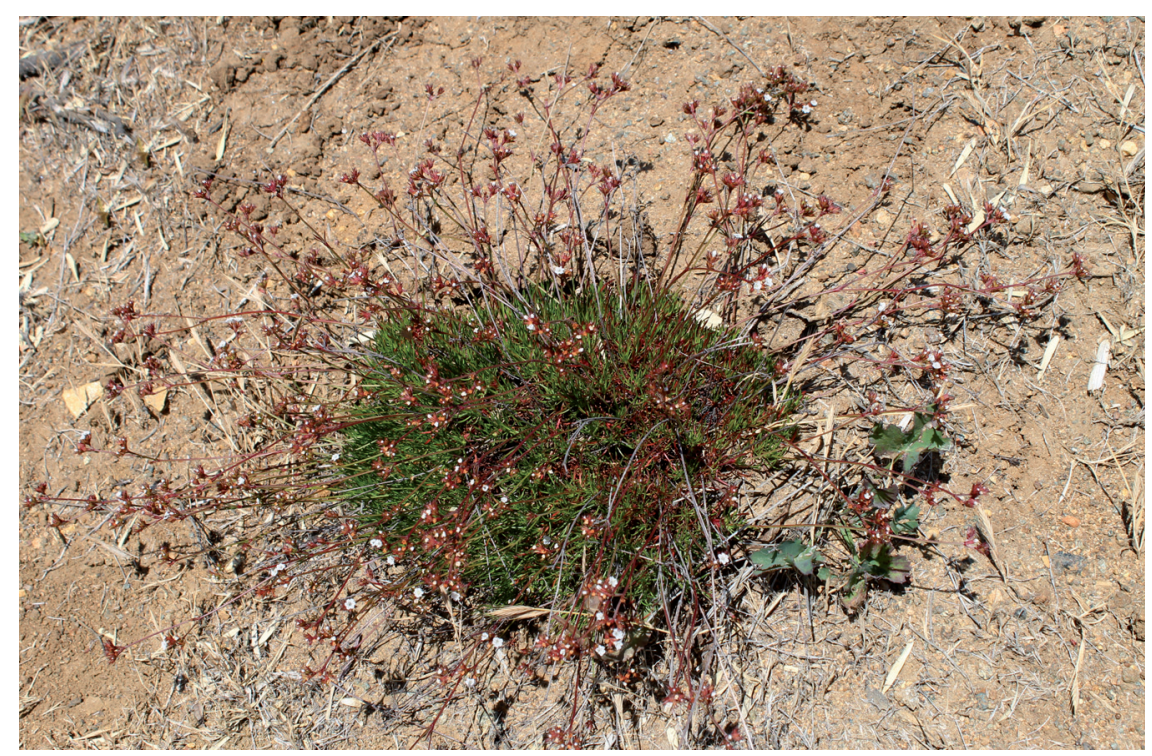

FIGURA 13. Chorizanthe novoana, hábito de una planta florecida. Laguna Verde, Región de Valparaíso. Fotografía de O. Fernández. / Chorizanthe novoana, habit of a flowering plant. Laguna Verde, Región de Valparaíso. Photo: O. Fernández. 
Maipo, 10-XII-1985, D. Aravena s/n (SQF 19235). Reserva nacional Río Clarillo, II-2004, F. Romero \& G. Aldunate 30 (CONC). Pirque, cerro Blanco, 11-V-1970, M. Mahu s/n (CONC 37049). Región de O’Higgins, Prov. Cachapoal, río Cachapoal, XII-1828, C. Bertero s/n (SGO 47971). Reserva nacional Río Los Cipreses, camino a Carrizal, 1131 m s.n.m., 30-XII-2005, L. Faúndez \& B. Larraín 1217 (CONC).

I.13. Chorizanthe peduncularis Benth. Trans. Linn. Soc. London 17: 416. 1836. TIPO: "Andes chilenses, 1831", Cuming 205 (holotipo, K000532039; isotipos E00514675! G00437264!).

Hierbas perennes. Tallos floríferos herbáceos (escapos), de hasta $50 \mathrm{~cm}$ de altura, con tricomas breves, poco aparentes, pero densos. Hojas en su mayor parte aglomeradas en la base de la planta, seríceo-pilosas en ambas caras; las de la base forman un braquiblasto en la base de las hojas viejas; láminas lineares, de 1-2,5 x 0,1-0,2 cm, apenas mucronadas. Los dicasios forman una sinflorescencia densa con aspecto de glomérulo, de 0,9-1 $\mathrm{cm}$ de largo; pedúnculos ramificados dicotómicamente o simples; brácteas en verticilos de tres, de 1-1,2 cm de largo; bractéolas en verticilos de tres, ciliadas en los márgenes, aovado-lanceoladas, base ensanchada, de 6- 7 $\mathrm{mm}$, mucronadas. Involucro de color pajizo, de 7-8 $\mathrm{mm}$, con el retículo marcado; lóbulos pilosos, rectos, poco uncinados, de 3-4 $\mathrm{mm}$ de largo. Perigonio de tépalos blancos, de $7 \mathrm{~mm}$, casi glabro, el tubo con el anillo de glándulas poco evidente; estambres, nueve. Aquenio glabro, de 4,2 $\mathrm{mm}$.

DisTRIBUCIÓN GEOGRÁFICA

Especie endémica de la cordillera de la Costa de las regiones de Valparaíso y Metropolitana.

\section{OBSERVACIONES}

Es similar a C. virgata Benth., pero las inflorescencias y los lóbulos del involucro son más largos. Existen pocas colecciones; al parecer tiene una distribución muy estrecha. Materiales estudiados: Región de Valparaíso, prov. Quillota, parque nacional La Campana, sector de Ocoa, ruta a las cascadas, 951 m s.n.m., 28-XI-2004, P. Baxter, M.F. Gardner, P. Hechenleitner, P.I. Thomas \& C. Zamorano s/n (CONC 176663; SGO 163181). Región Metropolitana, prov. Chacabuco, cerro El Roble, 2-XII-1973, O. Zollner 7753 (CONC). Caleu, ladera sur, 03-1971, A. Troncoso s/n (SGO 128148). Arriba de La Capilla, cima entre Caleu y La Dormida, 1290 m s.n.m., 10-II-2005, M. Rosas 2295 (CONC). Altos de Chicauma, camino de subida al tranque 1, 1400 m s.n.m., 10-I-2003, N. García 3814 (CONC).

I. 14. Chorizanthe rosasii Teillier \& Macaya, Novon 26: 50-51. 2018. TIPO: Chile, Región de Coquimbo, prov. Limarí: cerro de Guatulame, 3052'S-7054' W, 1765 m s.n.m., 7-XI-2006, M. Rosas 4149 (holotipo, CONC!).

Subarbustos, apenas leñosos en la parte basal. Tallos floríferos de hasta $20 \mathrm{~cm}$ de largo. Hojas con vaina anular, breve; lámina verde, algo vellosa en ambas caras, linear a linear-lanceolada, de 10-25 x 2-4 mm, ápice agudo. Los dicasios forman sinflorescencias con aspecto de umbelas más o menos densas; pedúnculos de $10-15 \mathrm{~cm}$ de largo, con 2-3 ramas; brácteas tres en cada nudo, similares a las hojas, de 5-10 mm de largo; seríceo-vellosas, ápice agudo; bractéolas similares a las brácteas, pero menores. Involucros de hasta $6 \mathrm{~mm}$ de largo; amarillentos, apenas vellosos por la parte externa y glabro en la interna; retículo conspicuo; apéndices apenas uncinados. Perigonio de $4 \mathrm{~mm}$ de largo, piloso; anillo de glándulas, piloso, tépalos blancos (Fig. 14).

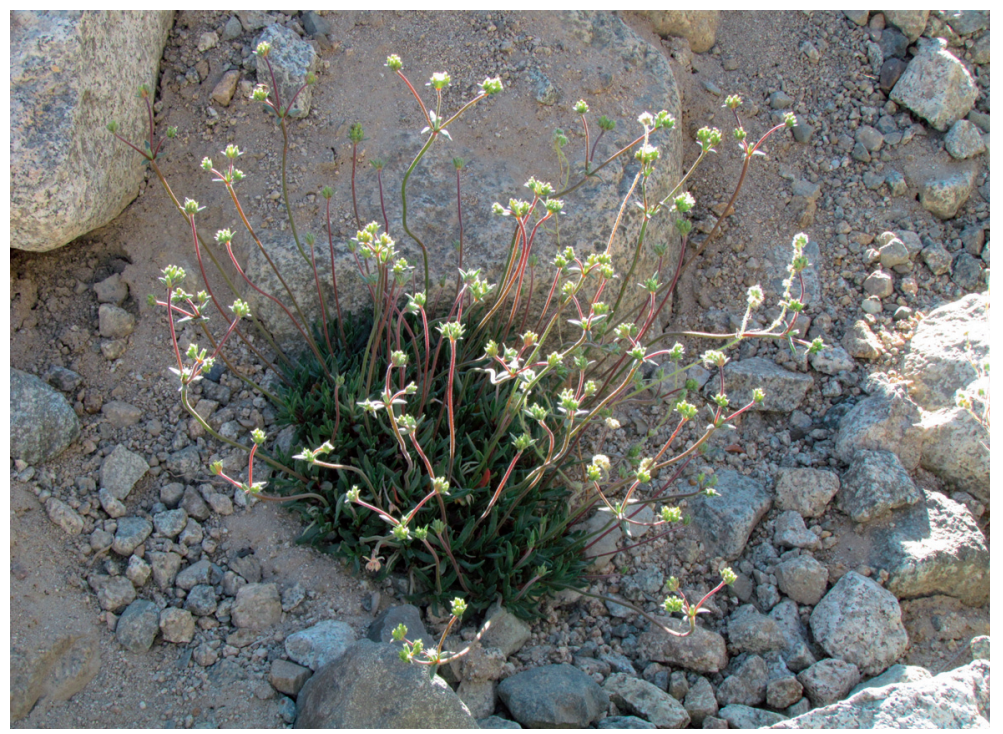

Figura 14. Chorizanthe rosasii, hábito de una planta con las yemas florales. Camino a la bocatoma de la central Los Molles, Región de Coquimbo. Fotografía de S. Teillier. / Chorizanthe rosasii, habit of a plant with floral buds. Road to Central Los Molles, Región de Coquimbo. Photo: S. Teillier. 
DISTRIBUCIÓN GEOGRÁFICA

Se encuentra desde la Región de Atacama a la de Coquimbo; crece en sitios pedregosos, en las cordilleras, entre 1700 y 2600 m s.n.m.

\section{OBSERVACIONES}

Corresponde a la forma de alta cordillera del grupo de los arbustos y subarbustos relacionados con C. macraei que incluye a $C$. umbellata y $C$. viridis. Por el escaso desarrollo leñoso de la parte aérea fue descrita como planta herbácea por Teillier \& Macaya (2018).

\section{Material estudiado}

CHILE, Región de Atacama, prov. Huasco, río Valeriano entre quebrada Yerba Buena y La Junta de Valeriano, 18002200 m s.n.m., 28-I-1983, C. Marticorena, M. Kalin-Arroyo \& C. Villagrán 83-641(CONC). Región de Coquimbo, prov. Elqui, camino internacional a San Juan, entre Juntas y embalse La Laguna, km 4, 2100 m, 6-01-1967, M. Ricardi, C. Marticorena \& O. Matthei 1713 (CONC). Junta del río Toro, 2060 m, 14-11-2001, C. Aedo 6888 (CONC). Prov. Limarí, Los Molles (Ovalle), 2800 m s.n.m., 15-I-1972, O. Zollner 6049 (CONC). Central eléctrica Los Molles, 1945 m s.n.m., 20-XII-2005, M. Rosas 3265 (CONC). Central eléctrica Los Molles, bocatoma, 2610 m s.n.m., 27-XII2006, M. Rosas 4428 (CONC). Camino a la bocatoma de la central Los Molles, 1900 m, 10-XI-2017, S. Teillier, J. Macaya, P. Novoa \& O. Fernández, 8293 (CONC). Camino a la bocatoma de la central Los Molles, 1900 m, 10-XI2017, S. Teillier, J. Macaya, P. Novoa \& O. Fernández, 8294 (CONC). Central eléctrica Los Molles, acueducto, km 7,3, 2490 m s.m.n., 14-II-2007, M. Rosas 4717 (CONC). Río Grande, mina "Los Pingos", 2240 m s.n.m., 10-IV-2006, M. Rosas 3625 (CONC). Ovalle, Morro Blanco, 2100 m s.n.m., 16-I-1949, C. Jiles 1235 (CONC). Tulahuén, XI-1889, G. Geisse s/n (SGO 72888), cerro Guatulame, 935 m, 09-XI2017, S. Teillier, J. Macaya, P. Novoa \& O. Fernández 8295 (CONC).

I.15. Chorizanthe umbellata Phil., Linnaea 33: 225. $1864-$ 65. TIPO: "Ad Huanta et rio Turbio, prov. Coquimbo invenit, 1860-61", Volckmann s.n. (lectotipo, SGO 47984! designado por Reveal, Harvard Pap. Bot. (1): 147, 2004).

Subarbustos, ramas floríferas de $10-35 \mathrm{~cm}$ de alto. Tallos erguidos, los nuevos, apenas pilosos. Hojas con vaina anular adpreso-pilosa con el margen algo ciliado; láminas verde-grisáceas, adpreso-pilosas en ambas caras, lineares, de 0,5-2,5 x 0,1-0,2 cm, agudas o apenas mucronadas. Los dicasios forman sinflorescencias con aspecto de umbelas compuestas, rica y ampliamente ramificadas; pedúnculos de 2,5-3,0 cm de largo, ramificados en tres o raras veces bifurcados; brácteas, tres en cada nudo, similares a las hojas, pero más cortas; la siguiente ramificación con dos ramas bifurcadas a su vez; bractéolas en pares, de 2-3 $\mathrm{mm}$ de largo, glabras, pero con cilios en el margen. Involucros casi glabros en el exterior, de 4,5-5 $\mathrm{mm}$ de largo, estrechos, con el retículo marcado, lóbulos de 2-2,2 mm, ápice apenas uncinado. Perigonio de 3-4 $\mathrm{mm}$ de largo, glabro, tépalos rosados o blancos, glándulas del tubo presentes, glabras; androceo con nueve estambres (Fig. 15).

\section{DisTRIBUCIÓN GEOGRÁFICA}

Crece en los contrafuertes de la cordillera de los Andes y en los cordones transversales, en la Region de Coquimbo.

\section{OBSERVACIONES}

Subarbusto del grupo de especies relacionadas con $C$. macraei, se distingue de ella y de sus afines $C$. viridis y C. rosasii por el elevado nivel de ramificación de las inflorescencias y por comprender plantas normalmente más robustas. Reveal (2004) la incluyó erróneamente en la sinonimia de C. paniculata.

\section{Material estudiado}

CHILE, Región de Coquimbo, prov. Elqui, camino al embalse La Laguna a $15 \mathrm{~km}$ de La Junta, $2500 \mathrm{~m}$ s.n.m., 5-II-1963, M. Ricardi, C. Marticorena \& O. Matthei 706 (CONC). Vicuña, cuesta del Churque, 800 m s.n.m., 12-X-

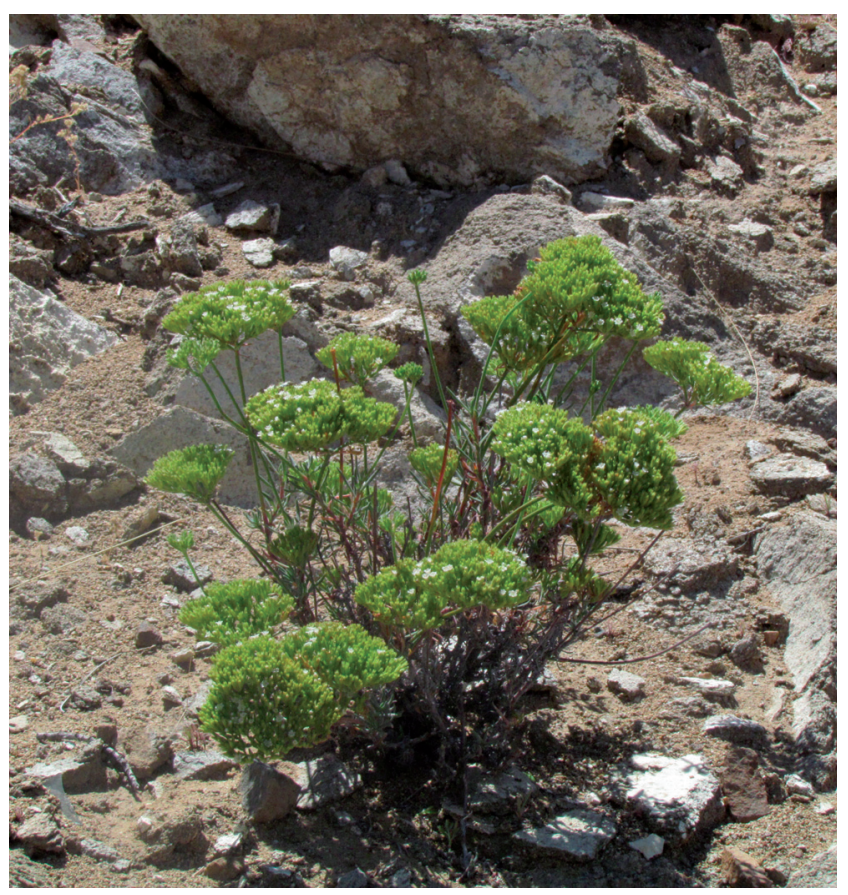

Figura 15. Chorizanthe umbellata, hábito de una planta con la sinflorescencia umbelada y flores abiertas. Camino Río Hurtado a Vicuña, bajando del portezuelo de Pangue, Región de Coquimbo. Fotografía de S. Teillier. / Chorizanthe umbellata, habit of a flowering plant showing the umbela like synflorescence. Road from Río Hurtado to Vicuña, Región de Coquimbo. Photo: S. Teillier. 
1940, G. Looser s/n (CONC 134561). Prov. Limarí, camino de Río Hurtado a Vicuña, portezuelo Tres Cruces, $1620 \mathrm{~m}$ s.n.m, 11-XI-2017, S. Teillier, J. Macaya, P. Novoa \& O. Fernández 8300 (CONC). Camino Río Hurtado a Vicuña, bajando hacia Vicuña, 910 m s.n.m., 11-XI-2017 S. Teillier, J. Macaya, P. Novoa \& O. Fernández 8301 (CONC). Camino Río Hurtado a Vicuña, bajando del portezuelo de Pangue 1645 m s.n.m., 11-XI-2017, S. Teillier, J. Macaya, P. Novoa \& O. Fernández, 8302 (CONC). Camino Río Hurtado a Vicuña, bajando del portezuelo de Pangue, 1645 m s.n.m., 11-XI-2017, S. Teillier, J. Macaya, P. Novoa \& O. Fernández 8303 (CONC). Camino Río Hurtado a Vicuña, bajando del portezuelo de Pangue, 11-XI-2017, 1645 m s.n.m., S. Teillier, J. Macaya, P. Novoa \& O. Fernández 8304 (CONC). Camino Río Hurtado a Vicuña, portezuelo de Pangue, 1510 m s.n.m., 11-XI-2017, S. Teillier, J. Macaya, P. Novoa \& O. Fernández 8305 (CONC). Camino Río Hurtado a Vicuña, bajando del portezuelo de Pangue, 895 m s.n.m., 11-XI2017, S. Teillier, J. Macaya, P. Novoa \& O. Fernández, 8307 (CONC). Prov. Limarí, camino de Pichasca a Río Hurtado, 925 m s.n.m., 11-XI-2017, S. Teillier, J. Macaya, P. Novoa \& O. Fernández 8309 (CONC). Camino de Combarbalá a Monte Patria, 7 km S de Las Coloradas, 800 m s.n.m., 09XI-2017, S. Teillier, J. Macaya, P. Novoa \& O. Fernández 8311 (CONC). Prov. Choapa, valle del río Chalinga, 2000 m s.n.m., 30-XI-2011, J. Macaya, R. Bustamante \& M. Sepúlveda, s/n (CONC). N de Illapel, estero Aucó, 555 m s.n.m., 8-XI-2005, M. Rosas 3017 (CONC).

I.16. Chorizanthe vaginata Benth. Trans. Linn. Soc. London 17: 417. 1836. TIPO: Valparaíso, 1832, Cuming 479 (holotipo, $\mathrm{K} \mathrm{cb} 000532036$ !; isotipos, CONC! G cb 00437252! GH cb 00435640! MEL cb 2366524!)
Chorizanthe vaginata Benth. var. maritima J. Rémy, Fl. Chil. 5: 288, 1851-1852. TIPO: "En los cerros de La Serena", Gay s.n. 1833 (lectotipo, G cb 00437251 designado aquí; isolectotipos, CONC!, F cb 0360589F!, G cb 00437250!, GOET cb 005983!).

Subarbustos, forman cojines densos, convexos o laxos. Tallos floríferos ramificados, de $20-60 \mathrm{~cm}$. Hojas con la vaina del largo del nudo, margen recto, ciliado; lámina pilosa, de forma romboidal hasta aovado-lanceolada, de 1-2 x 0,5-0,8 (1) $\mathrm{cm}$, mucronada. Los dicasios forman una sinflorescencia formada por 2-3 ramificaciones (dicotomías), pedúnculo basal de hasta $7 \mathrm{~cm}$, bifurcado; brácteas dispuestas en verticilos de dos, lanceoladas, fuertemente mucronadas, de 5-8 x 0,1-0,2 mm; bractéolas también en pares, aovadolanceoladas, de 2-5 $\mathrm{mm}$ de largo, margen membranoso y ciliado, con un mucrón de hasta $1 \mathrm{~mm}$. Involucro color marrón, ralamente piloso, de 8-9 mm, con retículo evidente, los lóbulos terminados en apéndices uncinados. Perigonio de 6-7 mm, parte medial del tubo con el anillo de glándulas amarillas de donde nacen pelos alargados, blanquecinos; tépalos blancos, pilosos en el dorso, con la nervadura central muy marcada en el dorso; estambres, nueve. Aquenio de 4 $\mathrm{mm}$ de largo (Fig. 16).

\section{DisTRIBUCIÓN GEOGRÁFICA}

Crece en las dunas consolidadas del litoral, desde la Región de Coquimbo (Los Vilos) hasta la localidad de Curanipe, en la Región del Maule.

\section{OBSERVACIONES}

La var. maritima según J. Rémy se diferenciaría por los tallos más gruesos y las vainas mayores y pilosas, caracteres que incluimos en la variación normal de la especie; la

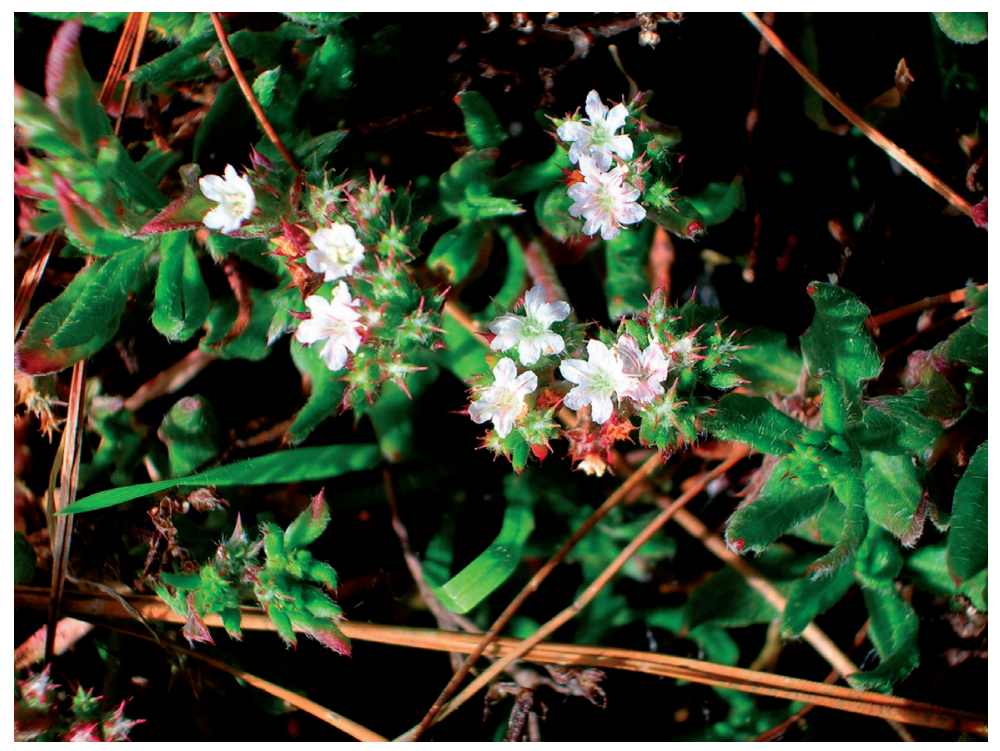

FIgURA 16. Chorizanthe vaginata, detalle de hojas y flores. Dunas de Concón, Región de Valparaíso. Fotografía de S. Teillier. / Chorizanthe vaginata, detail of leaves and flowers. Dunes of Concon, Región de Valparaíso. Photo: S. Teillier. 
variedad arida de J. Remy corresponde a $C$. glabrescens. Dado que todo el material que se encontró corresponde a copias del material de C. Gay etiquetado como colectado en "Chile" hemos tipificado con un material de G $(\mathrm{G} \mathrm{cb}$ 00437251); J. Reveal (2004) no lectotipificó esta variedad, pero calificó todo el material que revisó como isotipo; dado que la mayor parte de las carpetas tiene etiquetas de "duplicado" de P es extraño que no exista material típico digitalizado por ellos en su WEB. El ejemplar de C. Gay 988 (SGO) corresponde con esta especie, pero la localidad "Santiago, in subandinus" está errada.

\section{Material estudiado}

CHILE, Región de Coquimbo, prov. Choapa, carretera Panamericana al norte de Los Vilos, 17-III-1961, M. Ricardi, C. Marticorena \& O. Matthei 3 (CONC). Las Cañas, dunas, 350 m s.n.m., 30-XII-1966, Kohler 619 (CONC). Región de Valparaíso, prov. Petorca, Panamericana, $5 \mathrm{~km}$ al norte de Longotoma, 8-I-1967, M. Ricardi, C. Marticorena \& O. Matthei 1821 (CONC). Panamericana, $5 \mathrm{~km}$ al sur de Los Molles, 15-I-1964, C. Marticorena \& O. Matthei 546 (CONC). Pichicuy, dunas, 2 m s.n.m., 1-XI-1974, C. Marticorena, O. Matthei \& R. Rodríguez 142 (CONC). Laguna de Zapallar, I-1962, H. Gunckel s/n (CONC 82672). Prov. Valparaíso, dunas de Ritoque, 18-X-1951, H. Gunckel 46230 (CONC). Concón, "Roca Oceánica, 12-III-2002, M.T. Concha s/n (JBN 444). Dunas de Concón, hacia Cochoa, 26-I-2006, O. Fernández s/n (CONC 165356, JBN). Dunas de Concón, 15 m s.n.m., III-1966, O. Zollner 1042 (CONC). Laguna Verde, 120 m s.n.m., 7-X-1930, A. Garaventa 1646 (CONC). Prov. de San Antonio, El Canelillo (Algarrobo), 5 m s.n.m., XI-1965, S. Hein s/n (CONC 82664). El Canelillo, Algarrobo, 30 m s.n.m., E. Kausel 3822 (SGO). Rocas de Santo Domingo, 20-X-1950, A. Pfister \& M. Ricardi s/n (CONC 9755). San Antonio (de las Bodegas), IX-1853, P. Germain s/n (SGO 47961). El Convento-El Yali, XII- 1988, J. Araya 17 (SGO). Región del Maule, prov. Curicó, Iloca, 10-20 m s.n.m., II-1965, H. Gunckel 43364 (CONC). Prov. Talca, Constitución, II-1896, K. Reiche s/n (SGO 95825). Constitución, 10-15 m s.n.m., II-1951, M. Espinosa s/n (CONC 82620). Constitución, 12-III-1994, D. Benyamini $\mathrm{s} / \mathrm{n}$ (SGO 134274). Prov. de Cauquenes, costa, $10 \mathrm{~km}$ al sur de Curanipe, 5 m s.n.m., 26-I-1982, E. Ugarte 235 (CONC).

I.17. Chorizanthe virgata Benth., Trans. Linn. Soc. London, 17: 416, t. 19, f. 1. 1836. TIPO: "[Huerto Potrero], Andes of Chile, 1831", H. Cuming 205 (lectotipo, K cb 000532040! designated by J.Reveal, Phytologia 7: 346. 1992, isolectotipos, BM cb 000993216!, E cb 00514665!, E cb 005146641!, F cb 0360588F! fragmento).

Chorizanthe virgata Benth. var. tomentosa Benth in A. DC., Prodr. 14(1): 24. 1856. TIPO: Santiago, Chile, C. Wilkes s.n. (holotipo, $\mathrm{K}$, isotipo, GH cb 00036114 !)

Hierbas perennes, con rizomas. Tallos aéreos floríferos no leñosos (escapos), de 7-15 (20) $\mathrm{cm}$ de altura. Hojas aglomeradas en la base; vaina rojizo-escariosa, escasamente ciliada en el margen superior; lámina serícea, estrechamente linear-lanceolada, de 5-12 x 1-2 mm, brevemente mucronada. Los dicasios forman una sinflorescencia muy densa, con aspecto de glomérulo, de 5-6 $\mathrm{mm}$ de largo, con pedúnculos de 1,5-7 cm de largo, algunos bifurcados, otros solitarios; brácteas en verticilos de a tres, de 5-6 $\mathrm{mm}$ de largo, seríceas, mucronadas; bractéolas en verticilos de tres, seríceas, base ensanchada, de 2-3 x 1-1,2 mm, fuertemente mucronadas. Involucro seríceo, de 5-6 $\mathrm{mm}$ de largo, retículo cubierto por los tricomas, lóbulos largamente uncinados. Perigonio de $5 \mathrm{~mm}$ de largo, piloso en el exterior, anillo de glándulas presente, glabro. Androceo con nueve estambres. Fruto desconocido (Fig.17).

\section{DisTRIBUCIÓN GEOGRÁFICA}

Ha sido recolectada entre las regiones de Valparaíso (Colliguay) y O'Higgins (Alcones). Crece en el interior, en los cerros de la cordillera de la Costa.

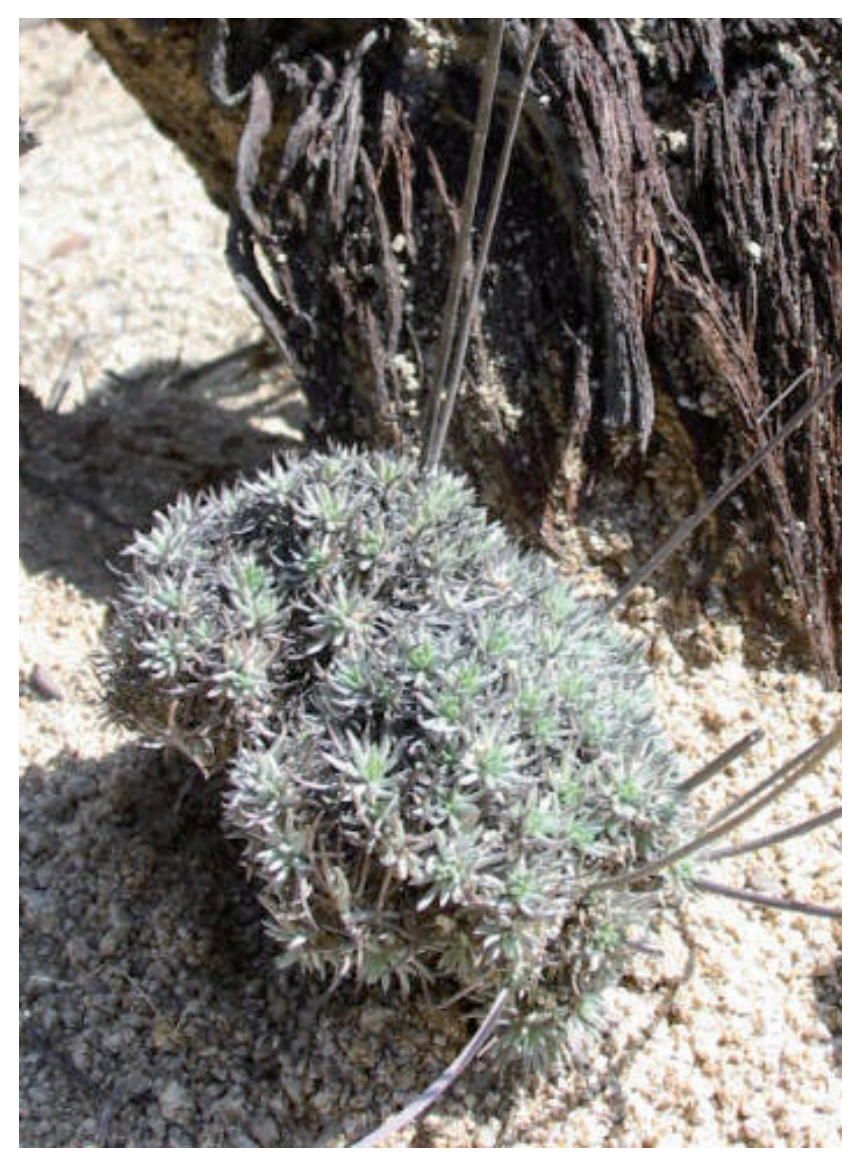

Figura 17. Chorizanthe virgata. Parte basal de una planta mostrando las hojas en rosetas. Colliguay, Región de Valparaíso. Fotografía de P. Novoa. / Chorizanthe virgata, base of a plant showing the leaves forming rosettes. Colliguay, Región de Valparaíso. Photo: P. Novoa. 
OBSERVACIONES

El ejemplar N. García et al. 2952, de Cocalán, Región de O’Higgins, difiere del tipo en el grado ramificación de la planta; a pesar de ello, las características de la inflorescencia coinciden bien con las de $C$. virgata.

\section{MATERIAL ESTUdiAdo}

CHILE, Región de Valparaíso, prov. Marga Marga, Colliguay, 24-XI-1969, 470 m s.n.m., O. Zollner 3547 (CONC); Colliguay, 15-III-2006, O. Fernández s/n (CONC 165340, JBN); Limache, cerro Cruz, 9-XII-1957, W.J. Eyerdam 10008 (SGO); Prov. Quillota, Quillota-La Campana, ladera oeste, 1500 m s.n.m., 30-XI-1947, F.L. Bultmann s/n (CONC 23337); Cerro La Campana, 1200 m s.n.m., 17-XII-1973, O. Zollner 8116 (CONC). Región Metropolitana, prov. Santiago, Santiago, XI-1830, C. Gay 1953 (SGO); hacienda Mansel, XII-1886, R.A. Philippi s/n. (SGO 95824); cuesta Zapata, cumbre, 800 m, 03-X-1941, C. Muñoz \& G. Johnson 2112 (SGO); cuesta Zapata, 10-I2003, A. Moreira s/n (SGO 154605). Región de O’Higgins, prov. Cachapoal, Cocalán, 197 m s.n.m., 22-XI-2005, N. García, F. Romero \& P. Contreras 2952 (CONC); prov. Cardenal Caro, entre Rosario y Alcones, 17-II-1968, M. Ricardi 5566 (CONC).

I.18. Chorizanthe viridis Phil., Anal. Univ. Chile 91: 498. 1895. TIPO: "Habitat in Andibus IIlapelinis loco dicto EI Peñón, januario 1888 lecta est", leg. R.A. Philippi s.n. (lectotipo, SGO 38666! designado aquí, isolectotipo, SGO 47955).

Subarbustos de 10-35 cm de altura. Tallos erguidos, los viejos con las cicatrices de las vainas foliares, los nuevos, pilosos y frecuentemente rojizos. Hojas con vaina anular; lámina, adpreso-pilosa, verde, linear, de 0,5-1,5 x 0,1$0,2 \mathrm{~cm}$, apenas mucronada. Algunas hojas viejas también toman un color rojo característico. Los dicasios forman sinflorescencias con aspecto de glomérulos más o menos compactos; pedúnculos verdoso-cenicientos, de 2-10 (25) $\mathrm{cm}$ de largo, raras veces ramificados; brácteas, tres en cada nudo, aovado-lanceoladas y agudas de 3-4 mm largo, pilosas en toda la superficie; bractéolas similares a las brácteas, concrescentes en la base, algo menores. Involucro glabrescente por fuera, de 5-6 mm de largo, marcadamente reticulado, lóbulos fuertemente uncinados en el ápice. Perigonio de 3-4 mm de largo, tépalos blancos, glabros, glándulas del tubo presentes, glabras; androceo con nueve estambres (Fig. 18).

DisTRIBUCIÓN GEOGRÁFICA

Crece entre las regiones de Coquimbo (provincia del Limarí) y Valparaíso (provincia de Petorca). Se recolectó en sitios rocosos con suelo muy delgado, frecuentemente rojizo o formado por cenizas volcánicas antiguas. En la cordillera de Petorca, sector El Durazno, a unos $1550 \mathrm{~m}$ de altitud, crece con especies muy particulares o escasas como Pycnophyllum lanatum Phil. y Brachyclados lycioides D. Don y algunas especies de carácter más bien andino como Azorella prolifera (Cav.) G.M. Plunkett \& A.N. Nicolas (Mulinum spinosum Cav.), Montiopsis sericea (Hook. \& Arn.) D.I. Ford y Calceolaria cana Cav.

\section{OBSERVACIONES}

Especie del grupo afín a C. macraei, junto con C. umbellata y $C$. rosasii, de los que se distingue por los pedúnculos solitarios o poco ramificados y el color verde del follaje, con muy escasa pilosidad, carácter anotado en la descripción por

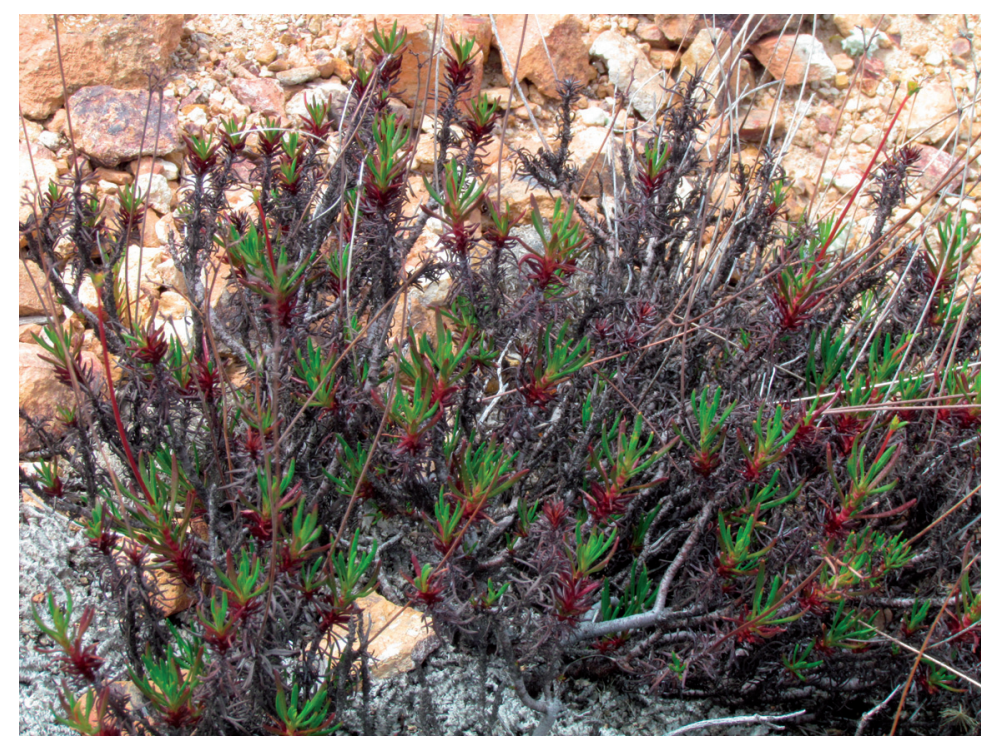

Figura 18. Chorizanthe viridis, hábito de una planta con yemas florales. Quebrada El Durazno, Petorca, Región de Valparaíso. Fotografía de S. Teillier. / Chorizanthe viridis, habit of a plant with floral buds. Quebrada El Durazno, Petorca, Región de Valparaíso. Photo: S. Teillier. 
R.A. Philippi quien agrega, además, el ápice fuertemente uncinado de los lóbulos del involucro. Poco recolectada y la mayor parte del material sin las sinflorescencias bien desarrolladas; requiere más estudio in situ para establecer su validez definitiva.

Se ha lectotipificado eligiendo como tipo al ejemplar SGO 38666, por existir un segundo ejemplar, SGO 47955.

\section{Material estudiado}

CHILE. Región de Coquimbo, prov. Limarí, Tulahuén, 1889, G. Geisse s/n (SGO 072888). Prov. Choapa, La Fraguita, Choapa, 1500-3000 m, XII-1894, P. Germain $\mathrm{s} / \mathrm{n}$ (SGO 095821). Cordillera de Illapel, 1500-2800 m, I-1906, K. Reiche s/n (SGO 047956). Alcaparrosa, cuesta El Espino, 1100 m s.n.m., 19-X-1941, G. Biese 2054 (SGO). Illapel, La Polcura, 3000 m s.n.m., 15-II-1962, C. Jiles 4254 (CONC). Valle de Chalinga, El Peñón, 1960 m s.n.m., 08XI-2017, S. Teillier, J. Macaya, P. Novoa \& O. Fernández 8292 (CONC). Cuncumén, 1400 m s.n.m., 19-X-1962, C. Jiles 4301 (CONC). Cuncumén, I-1860, L. Landbeck s/n (SGO 47983). Salamanca, 1780 m, 17-I-1993, Egli \& Leuenberger 2252 (SGO). Carén, 18-XII-1971, K. Beckett, M. Cheese \& J. Watson 4603 (SGO). Cajón de Pelambres, 1400 m s.n.m., X-1996, S. Teillier \& L. Faúndez 3840 (SGO). Región de Valparaíso, Prov. Petorca, Chincolco, 28XII-1972, O. Zollner 6749 (CONC). Quebrada El Durazno, 1490 m, 7-XI-2017, S. Teillier, J. Macaya, P. Novoa \& O. Fernández 8290 (CONC). Quebrada El Durazno, 1555 m s.n.m., 7-XI-2017, S. Teillier, J. Macaya, P. Novoa \& O. Fernández 8291 (CONC).

II. Subgénero Amphietes Rev. et Hardham.

II.1. Chorizanthe commissuralis J. Rémy, in Gay, Fl. Chil. 5: 287.1851-1852. TIPO: Chile, "que se cria en los lugares secos de Guanta; Copiapo, cerca de Chañarcillo, etc.,", $C$. Gays.n. (holotipo P cb 00734186, isotipos K cb 000532042!, $\mathrm{K}$ cb 000532043!, F cb 0360586F!).

Hierbas anuales. Tallos de $5-25 \mathrm{~cm}$ de altura, muy frágiles y quebradizos, densamente pubescentes pero se van haciendo más glabros en la medida que la planta envejece, las comisuras (nudos) fuertemente marcadas. Hojas sin vainas, escasa a densamente piloso-lanosas, dispuestas en su mayor parte en una roseta basal, simples, oblanceoladas a muy estrechamente oblongas, de 1-3 x 0,1$0,3 \mathrm{~cm}$, pseudopecioladas, enteras. Los dicasios forman una intrincada red de ramificaciones; brácteas opuestas, similares a las hojas, pero menores, 0,3-1 x 0,2-0,2 cm; bractéolas pilosas, lineares, de hasta $2 \mathrm{~mm}$ de largo, ápice uncinado. Involucro de 3-4 $\mathrm{mm}$ de largo, gris piloso, pero los tricomas caen a medida que madura el fruto, retículo presente pero notorio sólo una vez que caen los tricomas; ápice de los lóbulos fuertemente uncinado. Perigonio diminuto, de color blanco, los tépalos apenas más largos que el involucro. Androceo con tres estambres, apenas exertos de la corola, insertos en la parte superior del tubo de la flor. Fruto, un aquenio de 3-4 mm largo. (Figs. 19 y 20).

DisTRIBUCIÓN GEOGRÁFICA

Especie nativa de Chile, se encuentra desde la prepuna de la Región Arica y Parinacota hasta la Región de Coquimbo (Ovalle); además, se encuentra en el sur del Perú, en los departamentos de Moquegua y Tacna (Hardam \& Reveal, 1989) y en Argentina, en la Prov. de San Juan (Cialdella, 1992).

\section{OBSERVACIONES}

Es la única especie de Chorizanthe que crece en Chile como hierba anual. El tamaño de las plantas varía ampliamente según la disponibilidad hídrica; uno de los ejemplares de mayor tamaño fue recolectado cerca de la cuesta de Pajonales (Marticorena, Rodríguez \& Weldt 1702). La pilosidad de las hojas y los tallos varía desde laxamente pilosa hasta densamente pilosa, la parte superior de los tallos y los involucros se vuelven glabros en la madurez del fruto, frecuentemente los tallos pasan de color gris a rojizo en las ramas de la inflorescencia. Se registró también una variación en el largo del apéndice uncinado (entre 0,4 y $1 \mathrm{~mm}$ ).

\section{MATERial ESTUdiado}

CHILE, Región de Arica y Parinacota, prov. Arica, km 42 del camino de Poconchile a Zapahuira, 2300 m s.n.m., 3-V1972, M. Ricardi, E. Weldt \& M. Quezada 76 (CONC). Región de Tarapacá, prov. Tamarugal, Pica, quebrada Quisma, camino al salar de Huasco, límite con quebrada Infiernillo, 2450 m s.n.m., 5-VII-2000, S. Teillier 4813 (CONC). Camino de Huara a Colchane, quebrada Seca, 2015 m s.n.m., 2-IX-1997, C. Villagrán, F. Hinojosa \& C. Latorre 9001 (CONC). Región de Antofagasta, prov. Antofagasta, Taltal, 500 m s.n.m., X-1925, E. Werdermann 1860 (CONC). Taltal, Hueso Parado, 2-X-1953, M. Ricardi 2698 (CONC). Quebrada Cascabeles, costa norte de Taltal, X-1940, C. Grandjot 4567 (CONC). Prov. Loa, baños de Puritama, 3630 m s.n.m., 16-V-1997, M. Baeza, Aqueveque \& Kottirsch 494 (CONC). Camino a Río Grande, cerro del Inca, 3200 m s.n.m., 16-IV-1997, M. Kalin-Arroyo, L. Cavieres \& A. M. Humaña 97-692 (CONC). Región de Atacama, prov. Chañaral, El Salvador, 2870 m s.n.m., 23-XI-2011, S. Teillier \& A. Walkowiak 8090 (CONC). Caleta Obispito, 15 m s.n.m., 14-X-1965, M. Ricardi, C. Marticorena \& O. Matthei 1320 (CONC). Prov. Copiapó, llano de Varas, sector de la subestación Carrera Pinto, 1655 m s.n.m., 14-IX-2015, S. Teillier \& A. Zapata 8067 (CONC). Quebrada de Paipote, Puquios, 1250 m s.n.m., 6-I-1973, C. Marticorena, O. Matthei \& M. Quezada 489 (CONC). Prov. Huasco, camino a Carrizal Alto, 10-X-2010, P. Novoa s/n (JBN 1619). Carrizal, X-1965, A. Garaventa 4723 (CONC). $30 \mathrm{~km}$ al norte de Vallenar, 17-IX-1957, M. Ricardi \& C. Marticorena 4401 (CONC). Quebrada Agua Chica, 9 km 
N de Vallenar., 700 m s.n.m., 2-12-1987, M.O Dillon \& S. Teillier 5026 (F). Cajón del río Conay, cerca de San Vicente, 1500 m s.n.m., 13-X-1983, C. Marticorena 9554 (CONC). Río Laguna Grande, entre Las Papas y Potrero de Toledo, 2000-2400 m s.n.m., 19-I-1983, C. Marticorena, M. KalinArroyo \& C. Villagrán 83-361 (CONC). Cachiyuyo, 1 km al sur, 950 m s.n.m., 22-X-1971, C. Marticorena, R. Rodríguez \& E. Weldt 1765 (CONC). Camino a la mina Los Cristales por quebrada El Carbón, km 2, 1300 m s.n.m., 21-X-1971, C. Marticorena, R. Rodríguez \& E. Weldt 1702 (CONC). Cuesta de Pajonales, S. de Vallenar, 10-X-1987, S. Teillier 1040 (CONC). Huasco, $10 \mathrm{~km}$ al este, 8-X-1987, S. Teillier

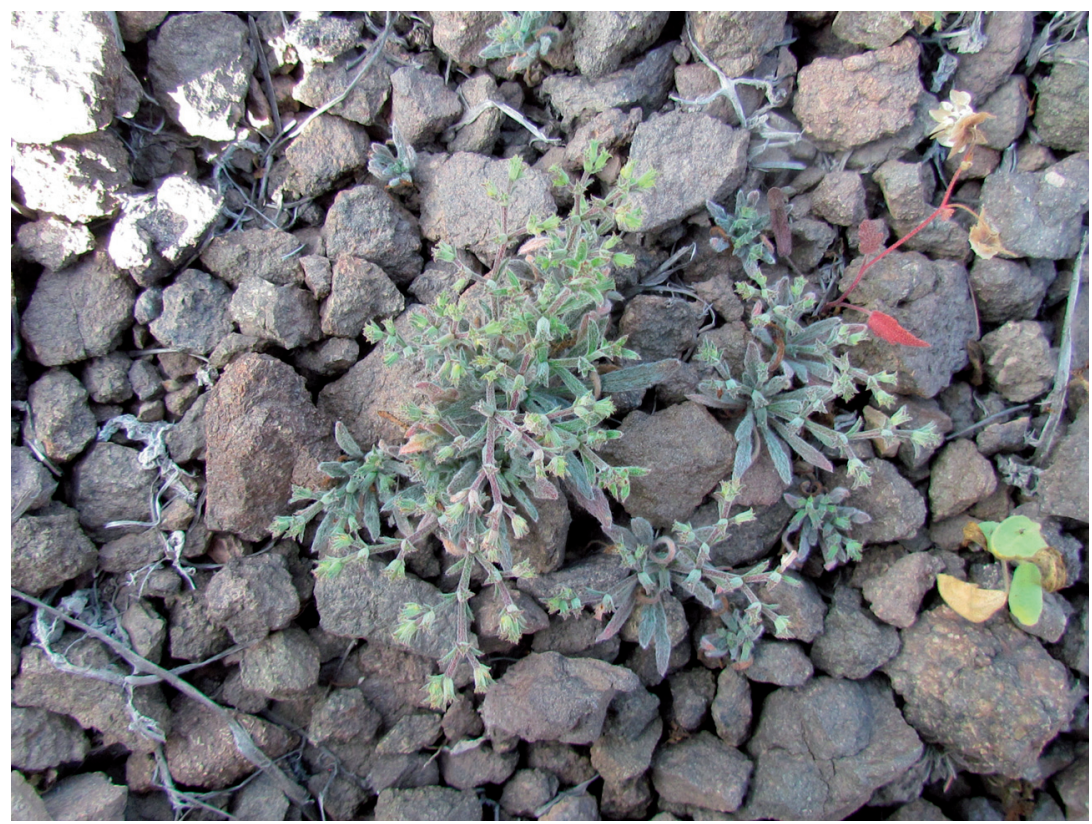

Figura 19. Chorizanthe commissuralis, forma con involucros pilosos, parte superior de una planta. Quebrada de Taltal, Región de Antofagasta. Fotografía de S. Teillier. / Chorizanthe commissuralis, a plant showing hairy involucres. Quebrada de Taltal, Región de Antofagasta. Photo: S. Teillier.

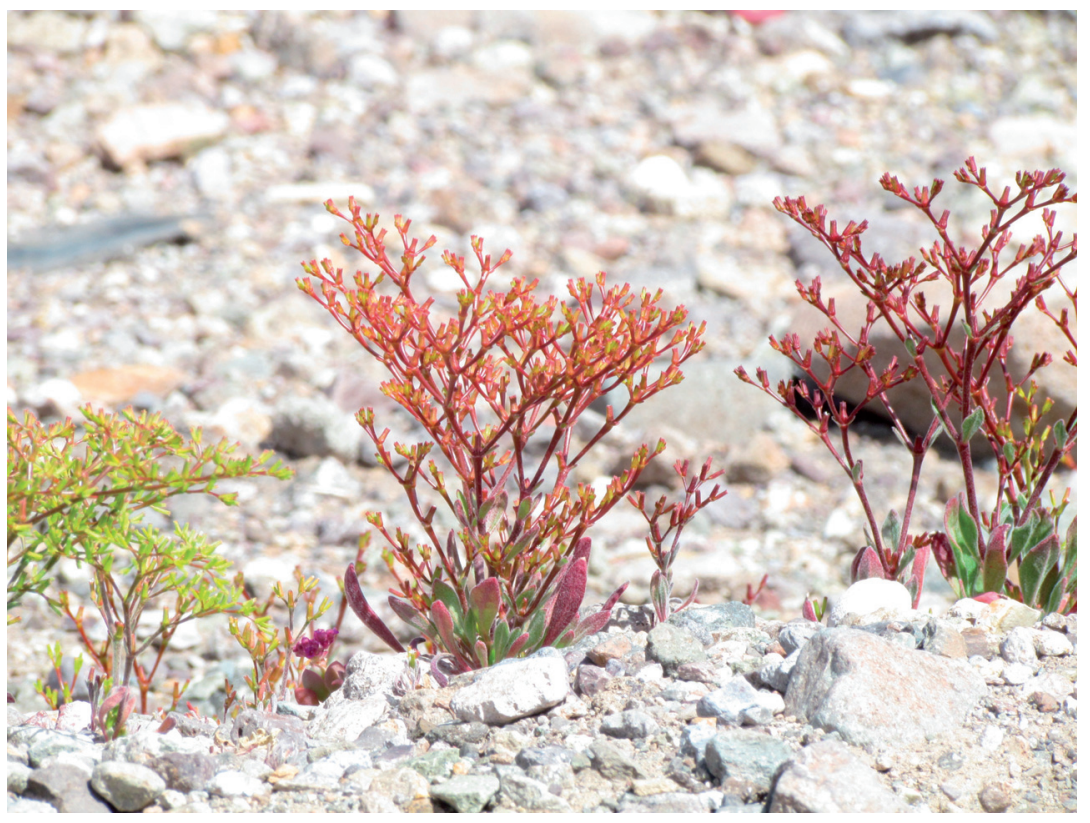

Figura 20. Chorizanthe commissuralis, forma con involucros glabros, hábito de una planta. Carrera Pinto, Llano de Varas, Región de Atacama. Fotografía de S. Teillier. / Chorizanthe commissuralis, a plant showing glabrous involucres. Carrera Pinto, Llano de Varas, Región de Atacama. Photo: S. Teillier. 
951 (CONC). Región de Coquimbo, prov. Elqui, Incahuasi, 25 km S., 10-X-1958, M. Ricardi \& C. Marticorena 4908 (CONC). Camino de Rivadavia a Paihuano, fundo Tres Cruces, 840 m s.n.m., 1-X-1948, F. Behn s/n (CONC 8440). Paihuano, cerro La Virgen, 1000 m s.n.m., 14-IX-1980, G. Montero 11667 (CONC). Camino de Montegrande a Pisco Elqui, IX-1984, S. Teillier \& P. García 460 (CONC). Prov. Limarí, Andacollo, 11-X-1958, M. Ricardi \& C. Marticorena 4948 (CONC). Ovalle, Carén, IX-1926, E. Barros 2197 (CONC). Ovalle, Corral Quemado, 1100 m s.n.m., 5-X1958, C. Jiles 3511 (CONC).

\section{INCERTAE SEDIS}

En SGO (47980) existe un ejemplar recolectado por C. Gay, posiblemente el mismo de la colección fotográfica del sitio web del herbario del Museo Nacional de Historia Natural de Paris (P-04995401) atribuido por C. Gay y J. Rémy a $C$. peduncularis Benth. Las hojas seríceo-vellosas y la sinflorescencia glomeruliforme inducen a incluirla en C. flavescens, aunque J. Rémy (1851) indique que fue recolectada en la "cordillera de Los Patos", localidad donde no crece esta especie.

\section{AGRADECIMIENTOS}

A los curadores de CONC y SGO por el préstamo y la consulta de ejemplares. A M.O. Dillon por las fotografías de ejemplares del Field Museum (F). Al Jardín Botánico Nacional, en particular a J. Stambuk y M. Bustamante por su apoyo logístico para la realización de las excursiones botánicas y a O. Fernández, por su invaluable trabajo en terreno. A dos revisores anónimos que hicieron un muy buen trabajo de revisión y edición.

\section{REFERENCIAS}

Bentham, G. 1836. On the Eriogoneae, a tribe of the order Polygonaceae. Transactions of the Linnean Society of London. 17: 401-420.

BRaKo, L., ZARUCCHI, J.L. 1993. Catalogue of the flowering plant and gymnosperms of Peru. Monographs in Systematic Botany Vol. 45. Missouri Botanical Garden, St. Louis, MO. $1286 \mathrm{pp}$.

Cialdella, A.M. 1992. Sobre la presencia del género Chorizanthe (Polygonaceae) en la Argentina. Hickenia 2: 49-52.

Cialdella, A.M. 1994. Chorizanthe. En: Kiesling, R. (ed.), Flora de San Juan, Vol. 1. Vázquez Mazzini Ediciones, Buenos Aires. Pp. 75-76.

Font-Quer, P. 1982. Diccionario de Botánica. Editorial Labor. Octava Edición. Madrid, España. 1244 pp.

Hardham, C.B., Reveal, J.L. 1989. A revision of the annual species of Chorizanthe (Polygonaceae: Eriogonoideae) Phytologia 66: 98-198.
Kempton, E.A. 2012. Systematics of Eriogonoideae s. s. (Polygonaceae). Systematic Botany 37: 723-737.

Marticorena, C., Quezada, M. 1985. Catálogo de la flora vascular de Chile. Gayana Botánica 42(1-2): 1-157.

MuÑoz, C. 1960. Las especies de plantas descritas por R.A. Philippi en el siglo XIX. Ediciones de la Universidad de Chile. Santiago de Chile. 189 pp.

Muñoz-Pizarro, C., Pisano, E. 1947. Estudio de la vegetación y flora de los parques nacionales de Fray Jorge y Talinay. Agricultura Técnica 2: 71-190.

Philippi, R.A. 1864. Plantarum novarum chilensium. Centuriae inclusis quibusdam Mendocinis et Patagonicis. Linnaea 33: 1-308.

PhiLIPPI, R.A. 1873. Descripción de las plantas nuevas incorporadas últimamente en el herbario chileno. Anales de la Universidad de Chile 43: 479-583.

PhilipPI, R.A. 1895. Plantas nuevas chilenas de las familias que corresponden al tomo $\mathrm{V}$ de la obra de Gay (continuación). Anales de la Universidad de Chile 90: 607-625.

ReIche, K. 1896-1911. Flora de Chile. Vols. I-VI. Impr. Cervantes, Santiago de Chile.

RÉmy, J. 1851. Chorizanthe. En: Gay, C., Historia física y política de Chile, Botánica [Flora Chilena], vol. 5. En casa del autor, Paris, y Museo de Historia Natural de Santiago, Chile.

Reveal, J.L. 1978. Distribution and phylogeny of Eriogonoideae (Polygonaceae). In: Harper, K.T., Reveal, J.L. (eds.), Intermountain Biogeography: A Symposium. Pp. 169190. Great Basin Naturalist Memoirs, No. 2. Brigham Young University Press, Provo, UT.

Reveat, J.L. 2004. Nomenclatural summary of Polygonaceae subfamily Eriogonoideae. Harvard Papers of Botany 9(1): 143-230.

Reveal, J.L. 2005. Polygonaceae Jussieu subfam. Eriogonoideae Arnott. In: Flora of North America Editorial Committee (eds.), Flora of North America, Vol. 5. Pp. 218-478. Oxford University Press, New York.

Reveal, J.L., Hardham, C.B. 1989. A revision of the annual species of Chorizanthe (Polygonaceae: Eriogonoideae). Phytologia 66: 98-198.

Squeo, F., Arancio, G., Marticorena, C., Muñoz, M. 2001. Listado de las especies en categoría extinta, en peligro y vulnerable de la flora nativa de Coquimbo. En: Squeo, F., Arancio, G., Gutiérrez, J. (eds.), Libro rojo de la flora nativa y de los sitios prioritarios para su conservación: Región de Coquimbo. Pp. 41-52. Ediciones de la Universidad de La Serena. Chile.

Teillier, S., Macaya, J. 2018. Cinco nuevas especies de Chorizanthe (Polygonaceae-Eriogonoideae) del norte de Chile. Novon 26(1): 37-52.

UICN. 2012. Categorías y Criterios de la Lista Roja de la UICN: Versión 3.1. Segunda edición. UICN, Gland, Suiza y Cambridge, Reino Unido. Originalmente publicado como IUCN Red List Categories and Criteria: Version 3. Second Edition. (IUCN, Gland, Switzerland and Cambridge, UK 2012)

Zuloaga, A., Morrone, O., Belgrano, M.J. (eds.). 2008. Catálogo de la flora vascular del cono sur. Base de datos asociada en INTERNET: http://www2.darwin.edu.ar/Proyectos/ FloraArgentina/FA.asp (Accedido: Mayo 1, 2018). 


\section{ÍNDICE}

Amphietes 35, 56

Chorizanthe 35, 37

Chorizanthe commissuralis $\mathbf{5 6}$

Chorizanthe dasyantha 37, 42, 44

Chorizanthe densa 49, 50

Chorizanthe deserticola 43, 44

Chorizanthe fasciculata 37

Chorizanthe flavescens 39, 58

Chorizanthe frankenioides 39, 40, 42, 47

Chorizanthe gajardoi $\mathbf{4 0}$

Chorizanthe glabrescens 40, 41, 42, 44, 54

Chorizanthe humilis 41, 42

Chorizanthe illapelina 39

Chorizanthe intricata 43, 44

Chorizanthe kingii 42, 43, 44, 47

Chorizanthe limariensis 44, 45, 47

Chorizanthe macraei 46, 52, 55

Chorizanthe macraei var. humilis 46

Chorizanthe mieresii 40, 46

Chorizanthe navasiae $\mathbf{4 8}$

Chorizanthe novoana 49

Chorizanthe paniculata 46, 49, 52

Chorizanthe parviflora 41, 42

Chorizanthe pauciflora 41, 42

Chorizanthe peduncularis 41, 51, 58

Chorizanthe ramosissima 46, 49, 50

Chorizanthe rosasii 46, 51, 55

Chorizanthe rosea 37

Chorizanthe stricta 44

Chorizanthe tenuis 41, 42, 43, 44

Chorizanthe umbellata 46, 52, 55

Chorizanthe vaginata 44, 45, 47, 53

Chorizanthe vaginata var. arida 41, 54

Chorizanthe vaginata var. maritima 53

Chorizanthe virgata 35, 41, 51, 54, 55

Chorizanthe virgata var. tomentosa 54

Chorizanthe viridis 46, 52, 55

Lastarriaea 35, 36

Lastarriaea chilensis 40, 42

Oxytheca 36

Trigonocarpus secundiflorus 49

LISTA DE RECOLECTORES Y EXSICCATA

Entre paréntesis el número del 1 al 19 que identifica a cada especie en el texto.

Aedo 6861 (5); 6888 (14), Arancio 15039 (9), Aravena s/n (SQF 19235) (12), Araya 17 (16)

Baeza, Aqueveque \& Kottirsch 494 (19), Barros 3727, s/n (CONC 14059) (2); s/n (CONC 82633) (12); 2197 (19), Baines, Gardner, Hechenleitner, Morter \& Rae 142 (6), Baxter, Gardner, Hechenleitner, Thomas \& Zamorano (CONC, 176643) (5); s/n (CONC 176663; SGO 163181) (13), Beckett, Cheese \& Watson 4708 (9); 4828 (12); 4603 (18), Behn (CONC 8589) (5); s/n (CONC 23342) (8); s/n (CONC 8440) (19), Benyamini s/n (SGO 134274) (16), Bertero (SGO 47971, isotipo) (12), Biese 2054 (SGO) (18), Bultmann s/n (CONC 23337) (17)
Cea s/n (CONC 173064) (3), Concha s/n (JBN 444) (16)

De Vore 1566 (1), Díaz s/n (CONC 82616) (12), Dillon, Dillon \& Poblete 5433 (5), Dillon \& Teillier 4997 (5); 5026 (19)

Egli \& Leuenberger 2252 (18), Espinosa s/n (CONC 82620) (16), Eyerdam 10008 (17)

Faúndez \& Larraín 1217 (12), Fernández 559 (2); 105 (tipo de $C$. novoana) (11); s/n (CONC 165356) (16); (CONC 165340, JBN) (17), Fluhmannii (SGO 38661 lectotipo de C. fasciculata, SGO 47966 isolectotipo de C. fasciculata)

Garaventa 6188 (1);1646 (16); 4723 (19), García 3814 (13), García, Romero \& Contreras 2952 (17) Gay s/n (SGO 47947 isotipo de C. frankenioides) (3); Gay 1910 (lectotipo de C. tenuis), 1915 (paratipo de C. tenuis) (5); s/n (SGO 48001) (8); Gay 1953 (17), Geisse s/n (SGO 09582) (1); s/n (SGO 072888) (18), Germain s/n. (SGO 047993) (12); s/n (SGO 47961) (16); s/n (SGO 095821) (18), Grandjot 386 (7), Grandjot 4567 (19), Gunckel s/n (CONC 82672), 43364, 46230 (16)

Harvey (E00514678) (5), Hein s/n (CONC 82664) (16)

Jaffuel 3130 (12), Jiles 2679, 2797 (1); 1806, 2791 (2); 3919 (3); 4990, 690 (5); 3932, 4912 (6); 5860 (tipo de C. navasiae) (10); 1235 (14); 4254, 4301 (18); 3511 (19), Johnston 5777 (6)

Kalin-Arroyo, Cavieres \& Humaña 97-692 (19), Kausel 3822 (16), King s/n. (SGO 47948, lectotipo de C. kingii, s/n; SGO 386789 isolectotipo de C. kingii) (6); s/n. (SGO 038675) (9), Kohler, 200 (1); 589 (3); 619 (16)

Lammers, Rodríguez \& Baeza 6333 (1), Lammers, Baeza, Peñailillo, 7654 (5); 7784 (11), Landbeck s/n (SGO 38658 isolectotipo de C. rosea), s/n (SGO 47954 tipo de C. dasyantha), s/n (SGO 47973 lectotipo de C. rosea) (1); (SGO 47988 tipo de C. flavescens) (2); s/n (SGO 47983) (18), Landrum 11515 (5), Landrum \& Landrum 5658 (5), Larrañaga (SGO 479990, tipo de C. deserticola) (6), Looser s/n (CONC 134561) (15), López s/n (CONC 82630) (CONC 82637) (6)

Macaya, Bustamante \& Sepúlveda 3017 (4); s/n (CONC) (15), Madrid \& Larraín 242 (12), Mahu 1837 (1); s/n (CONC 37049) (12), Marticorena s/n (CONC 25387) (6); 9554 (19), Marticorena, Kalin-Arroyo \& Villagrán 83-641 (14); 83-361 (19), Marticorena \& Matthei 419 (2); 213 (6); 341 (8); 546 (16) Marticorena, Matthei \& Quezada, 627 (3); 489 (19), Marticorena, Matthei \& Rodríguez 346 (1); 429 (5); 28 (10); 142 (16), Marticorena, Rodríguez \& Weldt 1361 (1); 1640 (5); 1711 (8); 1702, 1765 (19), Marticorena, Stuessy \& Baeza 9949 (3), Marticorena \& Weldt 536 (12), Meza \& Villagrán 1018 (5), Mieres s/n (CONC 180039) (9), Mihoc 340 (8), Milner s/n. (CONC 23335), (CONC 2332) (12), Montero 7226 (1); 7652 (6); 11667 (19), Moreira 1438 (12); s/n (SGO 154605) (17), Muñoz 3301 (2), 4211 (8), 2005 (9); 920 (10), Muñoz \& Coronel 1288 (7), Muñoz \& Johnson 2029 (6), 2112 (17), Muñoz \& Meza 2206 (1), Muñoz \& Stebbins 8670 (2) 
Gayana Bot. 76(1), 2019

Navas 2833 (7); 2734 (12), Novoa 735 (1); s/n (JBN 1628) (3); s/n (JBN 1619) (19)

Ortega (SGO 47969, tipo de C. humilis) (5)

Peña s/n (SQF 3388) (6), Peralta s/n (SGO 047985) (8), Pfister \& Ricardi s/n (CONC 9755) (16), Philippi s/n (SGO 479999 tipo de $C$. illapelina) (2); s/n (SGO 95819), s/n (SGO 47991 tipo C. parviflora) (5); s/n (SGO 038662), s/n (SGO 47972 tipo de C. intrincata) (6); s/n (SGO 038659) (8); Philippi s/n (SGO 47949 tipo de C. densa), s/n (SGO 047995) (12); Philippi s/n. (SGO 95824) (17); s/n (SGO 038666 tipo de C. viridis) (18), Pisano \& Bravo 193, 319, 791 (6)

Reiche s/n (SGO 047992) (1); s/n (SGO 061779) (12); (SGO 95825) (16); s/n (SGO 047956) (18), Ricardi 2725, 3123 (6); 2145 (7); 5566 (17); 2698 (19), Ricardi \& Marticorena 3876 (6); (4297/682), (4280/665) (7); 4421/826 (9); 4401, 4908, 4948 (19) , Ricardi, Marticorena \& Matthei, 1814 (3); 1695 (6); 1713 (14); 706 (15); 1821 (16); 1320 (19), Ricardi, Weldt \& Quezada 76 (19), Rojas (SGO 47967, tipo de C. tenuis) (6), Romero \& Aldunate 30 (12), Rosas 8793, 8884 (4); 4063, 5940 (10); 2295 (13); 4149 (tipo de C. rosasii), 3265, 4717 (14); 3017 (15)

Saa s/n (CONC 82656) (7), Schlegel 3902 (5); 7910 (6); 5876 (12), Sparre 2572 (3), Stuessy \& Ruiz 12776 (8)
Taylor, Von Bohlen \& Marticorena 10796 (6), Teillier 929 (5); 996 (6); 951, 1040, 4813 (19), Teillier \& L. Faúndez 3840 (18), Teillier \& García 460 (19), Teillier, Macaya, Novoa \& Fernández 8182, 8185, 8186 (1); 8296, 8297 (2); 8193, 8194, 8196 (3); 8189, 8197, 8198, 8199 (5); 8208 (6); 8188 (tipo de C. limariensis), 8191, 8191-A, 8214, 8215, 8216 (7); 8201, 8202, 8203, 8204, 8205, $8206,8209,8210,8211,8212,8200$ (Tipo de C. mieresii) (9); 8185,8186 (10); 8293, 8295 (14); 8299, 8300, 8301, 8302, 8303, 8304, 8305, 8307, 8309, 8311 (15); 8290, 8291, 8292 (18), Teillier \& Márquez 4894 (7), Teillier, Rundel \& García 2937 (6), Teillier \& Walkowiak 8090 (19), Teillier \& Zapata 8067, Tepe, Marticorena \& Pelser 1733, 1773 (5), Torres \& Villagrán s/n (CONC 82665; SGO 126622) (8), Troncoso s/n (SGO 128148) (13)

Ugarte 235 (16)

Villagrán, Hinojosa \& Latorre 9001 (19), Villagrán, Torres \& Osorio s/n (SGO 126393) (8), Von Bohlen 467 (5)

Wagenknecht 937 (1), Werdermann 902 (7), Werdermann 1860 (19)

Zollner 9017 (5); 8326 (6); 4338, 10034 (12); 7753 (13); 6049 (14); 1042 (16); 3547, 8116 (17); 6749 (18)

Recibido: 09.09.2018

Aceptado: 28.05.2019 